\title{
Neuropeptidergic Signaling and Active Feeding State Inhibit Nociception in Caenorhabditis elegans
}

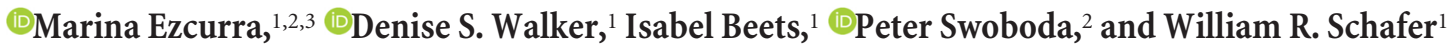 \\ ${ }^{1}$ Medical Research Council Laboratory of Molecular Biology, Cambridge CB2 0QH, United Kingdom, ${ }^{2}$ Department of Biosciences and Nutrition, Karolinska \\ Institute, Hälsovägen 7, S-141 83 Huddinge, Sweden, and 3'Institute of Healthy Ageing, and Research Department of Genetics, Evolution, and Environment, \\ University College London, London WC1E 6BT, United Kingdom
}

Food availability and nutritional status are important cues affecting behavioral states. Here we report that, in Caenorhabditis elegans, a cascade of dopamine and neuropeptide signaling acts to inhibit nociception in food-poor environments. In the absence of food, animals show decreased sensitivity and increased adaptation to soluble repellents sensed by the polymodal ASH nociceptors. The effects of food on adaptation are affected by dopamine and neuropeptide signaling; dopamine acts via the DOP-1 receptor to decrease adaptation on food, whereas the neuropeptide receptors NPR-1 and NPR-2 act to increase adaptation off food. NPR-1 and NPR-2 function cell autonomously in the ASH neurons to increase adaptation off food, whereas the DOP-1 receptor controls neuropeptide release from interneurons that modulate ASH activity indirectly. These results indicate that feeding state modulates nociception through the interaction of monoamine and neuropeptide signaling pathways.

Key words: C. elegans; chemosensation; dopamine; neuromodulation; neuropeptide

\section{Introduction}

Feeding state and nutritional status guide many behaviors and physiological responses in all animals. Both internal cues, such as satiety or starvation, and external cues indicating the presence or absence of a food source strongly influence brain states and the properties of neuronal circuits. In the nematode Caenorhabditis elegans, food availability and nutritional status have strong effects on several behaviors. Within minutes of leaving food, animals change their speed and locomotion and inhibit pharyngeal pumping and egg laying (Trent et al., 1983; Avery and Thomas, 1997; Sawin et al., 2000; Hills et al., 2004). More prolonged starvation has additional effects on diverse behaviors, such as chemotaxis and foraging, and also affects gene expression (Rogers et al., 2006; Suo et al., 2006; Tomioka et al., 2006; Hukema et al., 2008; Zimmer et al., 2009).

Received March 24, 2015; revised Dec. 23, 2015; accepted Jan. 18, 2016.

Author contributions: M.E., P.S., and W.R.S. designed research; M.E., D.S.W., and I.B. performed research; M.E., D.S.W., I.B., P.S., and W.R.S. analyzed data; M.E. and W.R.S. wrote the paper.

This work was supported by National Institutes of Health (NIH) Grant R01 DA018341, Medical Research Council Grant MC-A022-5PB91, and Wellcome Trust Investigator Award WT103784MA (W.R.S.) and from the Swedish Research Council, the Torsten Söderberg and Åhlén Foundations, and the Karolinska Institute Strategic Neurosciences Program (P.S.). I.B. is supported by a postdoctoral fellowship of the Research Foundation-Flanders. Some nematode strains used in this work were provided by the Caenorhabditis Genetics Center, which is funded by the NIH National Center for Research Resources. We thank Robyn Branicky and Andre Brown for comments on this manuscript and Emanuel Busch and Mario de Bono for sharing strains and constructs.

This article is freely available online through the J Neurosci Author Open Choice option.

Correspondence should be addressed to William R. Schafer, Medical Research Council Laboratory of Molecular Biology, Cambridge CB2 00H, UK. E-mail: wschafer@mrc-Imb.cam.ac.uk.

DOI:10.1523/JNEUROSCI.1128-15.2016

Copyright $\odot 2016$ Ezcurra et al.

This is an Open Access article distributed under the terms of the Creative Commons Attribution License Creative Commons Attribution 4.0 International, which permits unrestricted use, distribution and reproduction in any medium provided that the original work is properly attributed.
In C. elegans, monoamines have been shown to be particularly important molecules in the control of food-related behavior. For example, dopamine appears to be directly released by foodsensing neurons and affects food-dependent changes in locomotion, gene expression, and sensory perception (Sawin et al., 2000; Chase et al., 2004; Hills et al., 2004; Suo et al., 2006; Kindt et al., 2007; Ezcurra et al., 2011). Serotonin is required for fooddependent modulation of pharyngeal pumping, locomotion, and olfaction (Horvitz et al., 1982; Zhang et al., 2005; Harris et al., 2009), whereas octopamine mediates the control of olfaction and gene expression by feeding state (Suo et al., 2006; Wragg et al., 2007; Mills et al., 2012). Finally, tyramine has been shown to affect the control of foraging, egg laying, and pharyngeal pumping by feeding state (Rex et al., 2004; Alkema et al., 2005; Rex et al., 2005).

In addition to classical neurotransmitters, $C$. elegans has a complex system of neuropeptides consisting of $\sim 100$ peptide genes, encoding $>250$ peptides. Many of these are members of conserved families of bioactive peptides, including 40 insulin-like peptide genes and 34 of the FMRFamide-like peptide (FLP) family (Li and Kim, 2008). A few of these have been implicated in food-related behaviors (Harris et al., 2010), in particular INS-1 (Tomioka et al., 2006), FLP-18 (Cohen et al., 2009), and FLP-1 (Waggoner et al., 2000). Determining the function of many of these peptides has turned out to be a difficult task, because the precursor genes have overlapping functions and expression patterns, and neuropeptide receptors have the ability to bind to several peptides.

Here we report that neuropeptide signaling inhibits escape responses to noxious stimuli in C. elegans in the absence of food but not in the presence of food. Two receptors from the neuropeptide F/Y family, NPR-1 and NPR-2, act within the ASH noci- 
ceptor to inhibit avoidance by increasing sensory adaptation to repellents when food availability is low. Dopamine has the opposite effect of enhancing ASH responses and decreasing adaptation in the presence of food (Ezcurra et al., 2011). Our evidence suggests that the effects of dopamine are NPR-1 dependent and mediated indirectly through changes in neuropeptide signaling from the AUA interneurons. Thus, monoamine and neuropeptide modulators appear to interact to modify sensory perception in response to changes in environmental and behavioral states.

\section{Materials and Methods}

\section{Strains and culture}

Strains were maintained as described previously (Brenner, 1974). Hermaphrodites were used for all experiments. All strains were grown at $20^{\circ} \mathrm{C}$ on nematode growth medium (NGM) plates with OP50. The following strains were used: N2 (wild-type reference), CB1112 cat-2(e1112), CX4148 npr-1(ky13), DA609 npr-1(ad609), DA650 npr-1(g320), AQ2180 cat-2(e1112);ljEx95[sra-6::YC2.12;lin-15(+)], NY34 flp-8(pk360), RB982 flp-21(ok889), AX410 flp-18(db99), LX636 dop-1(vs101), and AQ1044 ljEx95 [sra-6::YC2.12;lin-15(+)]. The following strains were created: ljEx305[sra-6::npr-1;unc-122::gfp], AQ2803 npr-1(ky13);ljEx95 [sra-6:: YC2.12;lin-15(+)], AQ2933 npr-1(ky13);ljEx95 [sra-6::YC2.12;lin15(+)];ljEx305[sra-6::npr-1;unc-122::gfp], AQ2180 cat-2(e1112);ljEx95 [sra-6::YC2.12;lin-15(+)], AQ2310 cat-2(e1112);npr-1(ky13);ljEx95[sra-6:: YC2.12; lin-15(+)], AQ2928 ljEx466[dop-1::dop-1 RNAi;myo-2::gfp], AQ2929 ljEx467[flp-8::dop-1 RNAi;myo-2::gfp], AQ2931 ljEx469[flp-8:: dop-1 cDNA;myo-2::gfp];dop-1 (vs101), AQ2899 dop-1(vs101);ljEx454 [dop-1::dop-1;unc-122::gfp], AQ2897 dop-1(vs101);ljEx453[mec-7::dop-1; unc-122::gfp], AQ2942 dop-1(vs101);Ex [sra-6::dop-1;unc-122::gfp], AQ1364 $n p r-1(k y 13) ; n p r-2$ (ok419), AQ2193 npr-2(ok419);ljEx95[sra-6::YC2.12; lin-15(+)], AQ2056 npr-2(ok419), AQ2302 npr-1(ky13);npr-2(ok419); ljEx95[sra-6::YC2.12;lin-15(+)], AQ2387 npr-2(ok419);ljEx293[Psra6::npr-2;Pelt-2::mCherry], AQ2171 ljEx243[Psra-6::npr-2::gfp, Punc-122:: $g f p]$ line 1, AQ2169, ljEx243[Psra-6::npr-2::gfp, Punc-122::gfp] line 2, GA1720 npr-1(ky13);wuEx285[gpa-13::npr-1;Pmyo-2::gfp], GA1721 wuEx286[Pflr-4::unc-31senseRNAi;Pflp-8::unc-31antisenseRNAi;Pmyo2::gfp], GA1722 wuEx287[flp-8::unc-31;Pmyo-2::gfp], GA1723 npr-2 (ok419);wuEx288[gpa-13::npr-2;Pmyo-2::gfp], and GA1724 wuEx289[C41 G7.6::dop-1;Pmyo-2::gfp]; dop-1(vs101).

\section{Generation of transgenic animals}

Cameleon strains were generated by crossing ljEx955 sra-6::YC2.12] (Hilliard et al., 2005) into $n p r-1(k y 13)$ and cat-2(e1112). npr-1(ky13) was confirmed by PCR, followed by digest of the PCR product using DraI. cat-2(e1112) was confirmed by PCR, followed by digest using StyI.

Rescue plasmids. Plasmids were made using the MultiSite Gateway Three-Fragment Vector Construction kit (Invitrogen). Promoters were inserted into pDONR P4-P1R. Genomic DNA of $n p r-1$ and $n p r-2$ cDNA were inserted into pDONR 221. A pENTRY P2R-P3 containing the unc-54 3'UTR (kindly provided by Ithai Rabinowitch, MRC-LMB, Cambridge, UK) was used. $n p r-1$ and $n p r-2$ rescue constructs were generated by recombining the pENTRY and pDESTR4-R3 vectors using LR Clonase. sra- 6 pEntry was kindly provided by Emanuel Busch (MRC-LMB, Cambridge, UK) and contains a $3 \mathrm{~kb}$ region of the sra- 6 promoter. dop- 1 rescue constructs were made by PCR fusion of the promoter, the genomic DNA, and the unc-54 3'UTR. The flp-8::dop-1 rescue was made with cDNA instead of genomic DNA, and the cDNA was synthesized using SuperScript III One-Step RT-PCR System with Platinum Taq High Fidelity (Invitrogen). All rescue constructs were injected (Mello et al., $1991)$ at $50 \mathrm{ng} / \mu \mathrm{l}$ with coinjection marker $u n c-122:: g f p$ at $50 \mathrm{ng} / \mu \mathrm{l}$.

Rescue constructs by PCR fusion. Rescue constructs using the gpa-13 and C41G7.6 promoters were made using PCR fusion (Hobert, 2002) and injected at $50 \mathrm{ng} / \mu \mathrm{l}$ with $m y o-2:: g f p$ at $50 \mathrm{ng} / \mu \mathrm{l}$ as injection marker.

RNAi constructs and strains. dop-1 RNAi lines were generated as described previously (Esposito et al., 2007), and each RNAi strand was injected at $100 \mathrm{ng} / \mu \mathrm{l}$ with either $u n c-122:: g f p$ at $50 \mathrm{ng} / \mu \mathrm{l}$ or $m y o-2:: g f p$ at $5 \mathrm{ng} / \mu \mathrm{l}$ as coinjection marker. flp-8::unc-31 expressing strains were constructed using the same method, and each strand was injected at $50 \mathrm{ng} / \mu \mathrm{l}$ with myo-2::gfp at $50 \mathrm{ng} / \mu \mathrm{l}$ as injection marker. The AUA-specific unc-31 RNAi strain was made as described previously (Hamakawa et al., 2015). The unc-31 RNAi sense strand was expressed using the flr-4 promoter, and the antisense strand was expressed under the $f l p-8$ promoter. Each strand was injected at $50 \mathrm{ng} / \mu \mathrm{l}$ with $m y o-2:: g f p$ at $20 \mathrm{ng} / \mu \mathrm{l}$ as injection marker.

\section{Drop test assays}

For all behavioral assays, L4 stage animals were picked $20 \mathrm{~h}$ before the assay. The drop test and the adaptation drop test were performed on NGM plates and prepared for off-food and on-food assays as follows. For on-food plates, $25 \mu$ l of overnight culture of OP50 in Luria broth [LB; absorbance $(A)=0.5]$ was spread on each plate. For off-food plates, $25 \mu \mathrm{l}$ of LB was spread on each plate. All plates were allowed to dry for $1 \mathrm{~h}$ without lids and used after 1 additional hour for assays. Behavioral assays can be sensitive to environmental factors, such as humidity. We have noticed that the humidity levels of the plates have a strong effect on the adaptation phenotype, and animals adapt faster on wetter plates than on dry plates. Therefore, baseline levels of adaptation differ between experiments. Animals were picked off the culture plate using an eyelash pick and placed on a plate without food for a few seconds to prevent food from being transferred to the assay plates. The animals were then placed on the assay plate. Animals were allowed to settle for $10 \mathrm{~min}$ and then assayed using a capillary to deliver the repellent drop as described previously (Hilliard et al., 2002). For the drop test, 10 animals were assayed on each plate. All animals were stimulated every $60 \mathrm{~s}$, and the fraction of worms reversing was recorded. In the adaptation drop test, a single animal was picked to each plate and assayed every $10 \mathrm{~s}, 20$ times. The response to every drop was recorded, and the avoidance index was calculated by dividing the number of animals reversing with the number of animals tested. The tested repellents were $\mathrm{CuCl}_{2}$ (copper(II)chloride dehydrate; Sigma) and glycerol (Thermo Fisher Scientific). Repellents were dissolved and diluted in M13 buffer. Each experiment was performed blinded and on more than 2 different days.

For transgenic strains, we generated two independent transgenic lines from each transgene and analyzed at least 15 animals from each line, averaging the results from both lines.

\section{Calcium imaging experiments}

Sample preparation and delivery of stimulation. Animals were glued on $2 \%$ agarose pads made with neuronal buffer using cyanoacrylate glue (Nexaband S/C; Abbott Laboratories). The pad was placed briefly on ice during the gluing to constrict the animal's movements. The animals were placed under the microscope in a perfusion chamber (RC-26GLP; Warner Instruments) under constant flow rate $(0.4 \mathrm{ml} / \mathrm{min})$ of neuronal buffer using a perfusion pencil (AutoMate). Outflow was regulated using a peristaltic pump (Econo Pump; Bio-Rad). Repellents were delivered using the perfusion pencil and automated valves (EW-98302-20; Cole Parmer), controlled by Motorway software 2.5. The neuronal buffer contained $40 \mathrm{~mm} \mathrm{NaCl}, 10 \mathrm{~mm}$ HEPES-NaOH, pH 7.1, and $1 \mathrm{~mm} \mathrm{MgSO}_{4}$, and the osmolarity was adjusted to $350 \mathrm{mOsm}$ using glycerol. Copper and glycerol were dissolved in M13 buffer. For recordings with food, OP50 was grown overnight in $\mathrm{LB}(\mathrm{A}=0.5)$, and $50 \mathrm{ml}$ cultures were pelleted by centrifugation. The pellets were dissolved in neuronal buffer or repellent, to a final volume of $25 \mathrm{ml}$, and used within $1 \mathrm{~h}$. Adaptation was tested by first giving the animals a $3 \mathrm{~s}$ prechronic stimulation, followed by a $15 \mathrm{~s}$ chronic stimulation and a $2 \mathrm{~min}$ rest. Animals were then given a $3 \mathrm{~s}$ postchronic stimulation. The prechronic and postchronic responses were analyzed.

Calcium imaging and image analysis. Optical recordings were performed on a Zeiss Axioskop 2 upright compound microscope using a $63 \times$ Zeiss Achroplan water-immersion objective. Filter/dichroic pairs were as follows: excitation, 420/40 nm; excitation dichroic, $455 \mathrm{~nm}$; CFP emission, 480/30 nm; emission dichroic, $505 \mathrm{~nm}$; and YFP emission, 535/30 nm (Chroma Technology). The microscope was fitted with a Hamamatsu Orca ER CCD camera, a Hamamatsu W-View emission image splitter, and a Uniblitz Shutter (Vincent Associates). Images were acquired at $10 \mathrm{~Hz}$ using MetaVue 4.6 (Universal Imaging). Image analysis was performed as described previously (Kerr et al., 2000) using a 

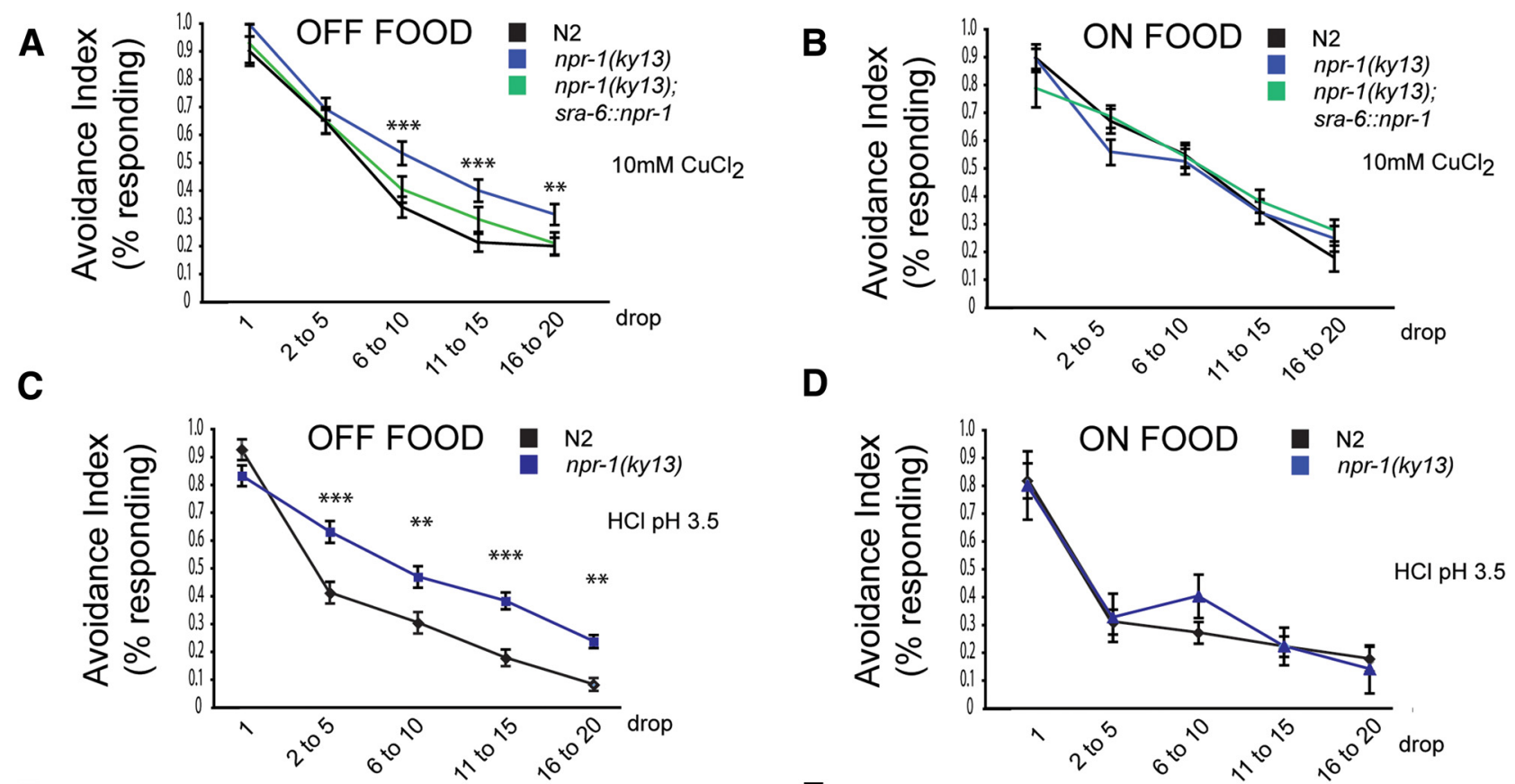

$\mathbf{E}$

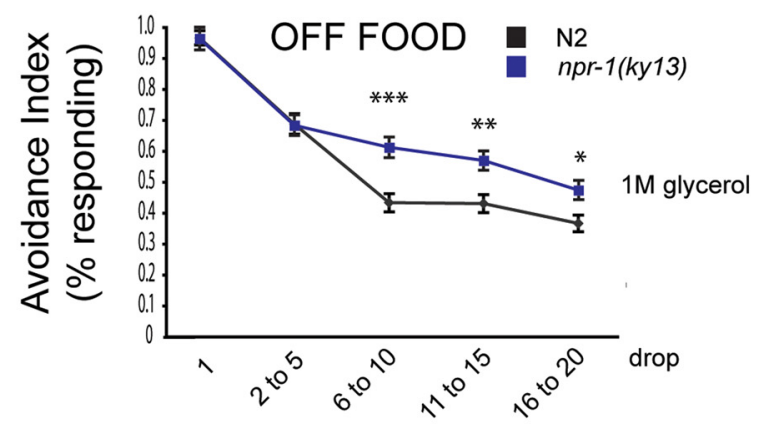

$\mathbf{F}$
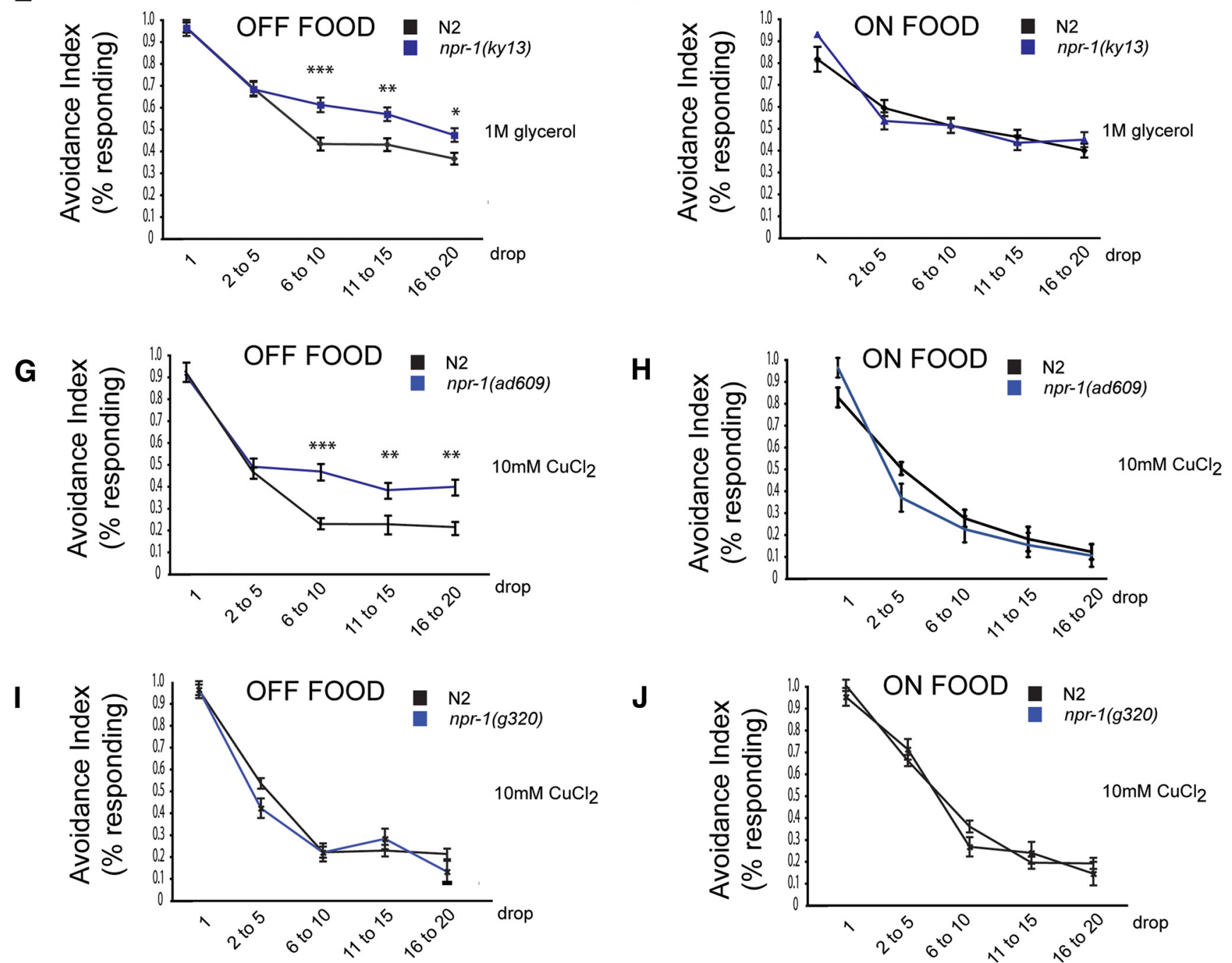

Figure 1. The neuropeptide receptor NPR-1 promotes sensory adaptation off food. $A-J$, Fraction of animals responding to repeated drops of chemical repellent. $A, n p r-1$ (ky 13 ) adapts slower than wild type to $10 \mathrm{~mm} \mathrm{CuCl}_{2}$ off food. $n=40$. Transgenic animals expressing genomic npr-1 DNA under the sra- 6 promoter (ASH, ASI, and PVQ) adapt like wild type. Two stable independent lines were analyzed, and the average of both lines is shown. $n=40 . B, n p r-1$ (ky13) animals adapt like wild type to $10 \mathrm{~mm} \mathrm{CuCl}$ on food. $n=24 . n p r-1$ (ky13), wild-type and rescued (Figure legend continues.) 
custom program written in Java, parameterized, and averaged using scripts written in MATLAB 6.5.1 (MathWorks). The ASH cell body was identified based on its position and tracked as described using custom software (Hilliard et al., 2005).

In vitro receptor activation assays

Activation of NPR-2 by candidate peptide ligands was monitored using an in vitro calcium mobilization assay as described previously (Janssen et al., 2008). Chinese hamster ovary (CHO) K1 cells stably overexpressing the mitochondrial-targeted apo-aequorin and the human $\mathrm{G} \alpha 16$ subunit were cultured and transfected with pcDNA3.1D::npr-2-cDNA. Cells for negative control experiments were transfected with an empty pcDNA3.1D vector. A peptide library of 262 synthetic $C$. elegans peptides was composed based on in silico predictions and in-house peptidomics data and custom synthesized by Thermo Fisher Scientific, GL Biochem, and Eurogentec. Receptor activating peptides were HPLC purified and tested in final concentrations from $10^{-4}$ to $10^{-10} \mathrm{M}$. Calcium responses were monitored as described previously (Janssen et al., 2008) for $30 \mathrm{~s}$ on a Mithras LB 940 luminometer (Berthold Technologies). The halfmaximal effective concentration $\left(\mathrm{EC}_{50}\right)$ values of peptide ligands were determined from concentration-response curves, which were constructed using a computerized nonlinear regression analysis with a sigmoidal concentration-response equation (Prism 6; GraphPad Software).

\section{Results}

\section{The neuropeptide receptor NPR-1 promotes adaptation to chemical repellents off food}

We demonstrated previously that escape responses to soluble repellents adapt more slowly in animals tested in the presence of a bacterial food source than in animals tested in the absence of food. This effect requires dopamine, which is released by neurons that directly sense bacteria in the environment (Ezcurra et al., 2011). To investigate whether other molecules also mediate the effect of feeding state on repellent adaptation, we screened through candidate monoamine and neuropeptide receptor genes for abnormal adaptation to copper. We found that animals carrying a null mutation in the neuropeptide receptor $n p r-1$, which is implicated in aggregation and other food-modulated behaviors (de Bono and Bargmann, 1998), adapted normally to repeated stimulation with $10 \mathrm{mM} \mathrm{CuCl}_{2}$ in the presence of food but showed reduced adaptation to copper in the absence of food (Fig. $1 A, B)$. We observed the same phenotype for other chemical repellents, including $1 \mathrm{M}$ glycerol and $\mathrm{HCl}$ at $\mathrm{pH} 3.5$ (Fig. $1 C-F$ ). Thus, $n p r-1$ loss of function caused food-deprived animals to show behavior characteristic of feeding animals. This adaptation phenotype was rescued by expression of an $n p r-1(+)$ transgene in ASH under the sra-6 promoter (Fig. $1 A$ ), which drives expression in ASH and other neurons. To ensure that NPR-1 functions in $\mathrm{ASH}$, we also constructed a transgene under the gpa-13 promoter, which only overlaps with sra-6 in ASH. This transgene also rescued the adaptation phenotype (see Fig. 3D), suggesting that NPR-1 functions in ASH to modulate repellent sensation in the absence of food.

The $n p r-1$ allele found in the standard C. elegans strain N2 differs from the allele found in naturally occurring $C$. elegans

\section{$\leftarrow$}

(Figure legend continued.) $\quad$ animals adapt at the same rate on food. $n=21 . \mathrm{C}, n p r-1(\mathrm{ky} 13)$ adapts slower than wild type to $\mathrm{HCl}$, pH 3.5, off food. $n=38 . \mathbf{D}, n p r-1$ (ky13) animals adapt like wild type to $\mathrm{HCl}$, pH 3.5, on food. $n=19 . E, n p r-1(\mathrm{ky} 13)$ adapts slower than wild type to $1 \mathrm{M}$ glycerol off food. $n=37 . F, n p r-1(k y 13)$ animals adapt like wild type to $1 \mathrm{~m}$ glycerol on food. $n=22$. G, npr-1(ad609) adapts slower than wild type off food. $n=34$. $\mathbf{H}, n p r-1$ (ad609) animals adapt like wild type on food. $n=20 . I, n p r-1(g 320)$ adapts like wild type off food. $n=$ 29. J, npr-1 (g320) animals adapt like wild type on food. $n=19$. Behavioral data were analyzed using Student's $t$ test. ${ }^{*} p<0.05,{ }^{* *} p<0.01,{ }^{* * *} p<0.001$. populations (McGrath et al., 2009). The N2 allele, which is thought to have arisen during cultivation in the laboratory, encodes a receptor with a valine residue at position 215; this $n p r-$ $1(215 \mathrm{~V})$-encoded variant has heightened activity relative to the $n$ pr-1 $(215 F)$ allele found in wild C. elegans populations carrying a phenylalanine residue at position 215 . Because the low-activity npr-1(215F) strains share behavioral and other phenotypes with npr-1 null mutants (de Bono and Bargmann, 1998; Styer et al., 2008), we wondered whether the effect of food on repellent adaptation might be specific to strains carrying the laboratoryselected $n p r-1(215 \mathrm{~V})$ allele. To examine this possibility, we compared the escape responses to copper on and off food of $n$ pr-1 (g320), which harbors the $n p r-1(215 F)$ allele in an otherwise $\mathrm{N} 2$ background, with N2. We observed no significant differences in copper adaptation between this strain and N2 either on or off food (Fig. $1 G, H$ ), indicating that food modulation occurs in both $n p r-1(251 \mathrm{~V})$ and $n p r-1(215 F)$ strains. In contrast, a second $n p r-1$ null allele (ad609) showed the same decreased adaptation off food that was observed in the npr-1(ky13) null mutant (Fig. $1 G, H)$. Thus, both the $215 \mathrm{~V}$ and $215 \mathrm{~F}$ variants of NPR-1 appear to mediate enhanced adaptation to soluble repellents in the absence of food.

\section{NPR-1 affects sensory adaptation in ASH chemosensory neurons}

The ASH neuron has been shown to play a critical role in the sensation of multiple soluble repellents, including copper, glycerol, and acidic pH. To determine whether NPR-1 affects the repellent responses of the $\mathrm{ASH}$ neurons themselves, we performed calcium imaging experiments using the genetically encoded calcium indicator cameleon. In these calcium imaging experiments, we observed that $n p r-1(k y 13)$ animals showed normal initial $\mathrm{CuCl}_{2}$-evoked calcium responses in $\mathrm{ASH}$ in both the presence and absence of food (Fig. $2 B, D, E$ ). We then tested adaptation after prolonged exposure to copper. We found that, in wild-type animals, the ASH neurons adapted more strongly in the absence of food than in the presence of food (Fig. 2A,D,E). When we tested npr-1(ky13) animals, we found that they adapted less than wild type in the absence of food (Fig. $2 A, B, D, E$ ) but adapted to the same degree as wild type in the presence of food. The calcium imaging phenotype, like the behavioral defect, was rescued by expression of an $n p r-1(+)$ transgene in ASH under the sra-6 (Fig. 2C-E) or the gpa-13 promoter. Together, these results indicate that NPR-1 functions in ASH to modulate repellent responses in the absence but not the presence of food. This suggests that the NPR-1 receptor responds to a ligand (or ligands) released under conditions in which food is absent.

\section{NPR-1 and NPR-2 act in the same pathway to affect adaptation in ASH}

In addition to NPR-1, we found a closely related neuropeptide receptor that also shows defective adaptation to noxious stimuli. Animals carrying a null mutation in $n p r-2$, a deletion that takes out most of the coding sequence, have a phenotype similar to $n$ pr-1 mutants; they respond normally to initial stimulation with $10 \mathrm{mM} \mathrm{CuCl}_{2}$ but adapt slower to repeated stimulation in the absence of food (Fig. 3A). Furthermore, calcium imaging experiments showed that, in $n p r-2$ (ok419) animals, the ASH neuron shows normal initial responses and suppressed adaptation to repeated stimulation with $\mathrm{CuCl}_{2}$ in the absence of food but not in the presence of food (Fig. 3E-G). NPR-2 is widely expressed in the nervous system, including in the ASH neuron (Luo et al., 2015). We expressed an $n p r-2(+)$ transgene under either the 


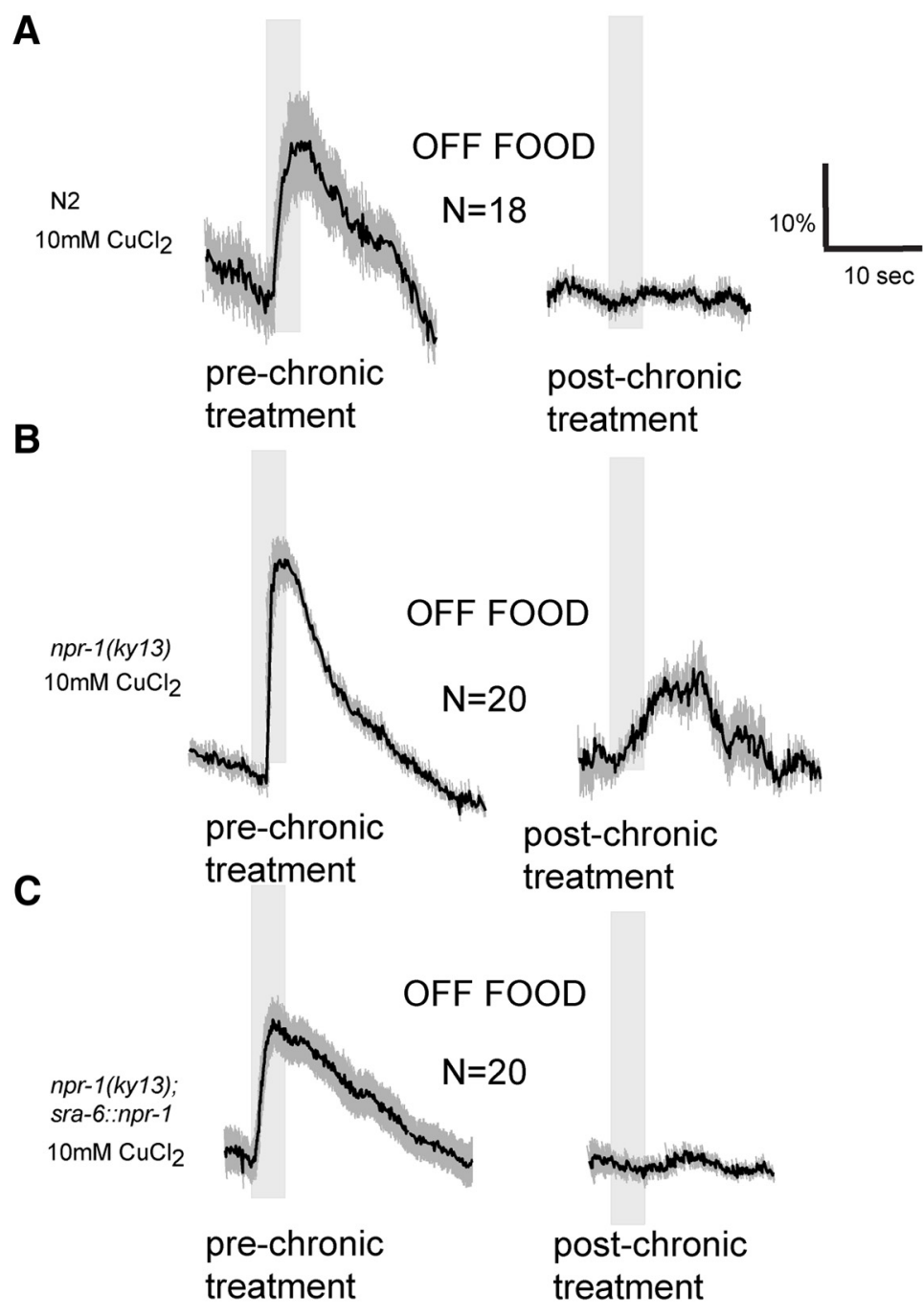

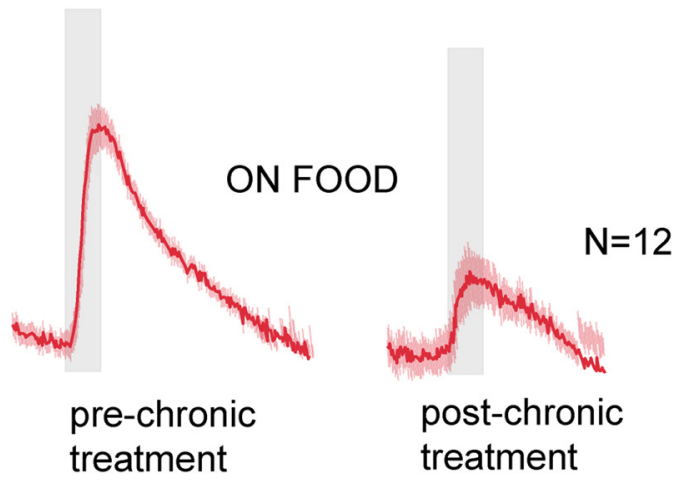
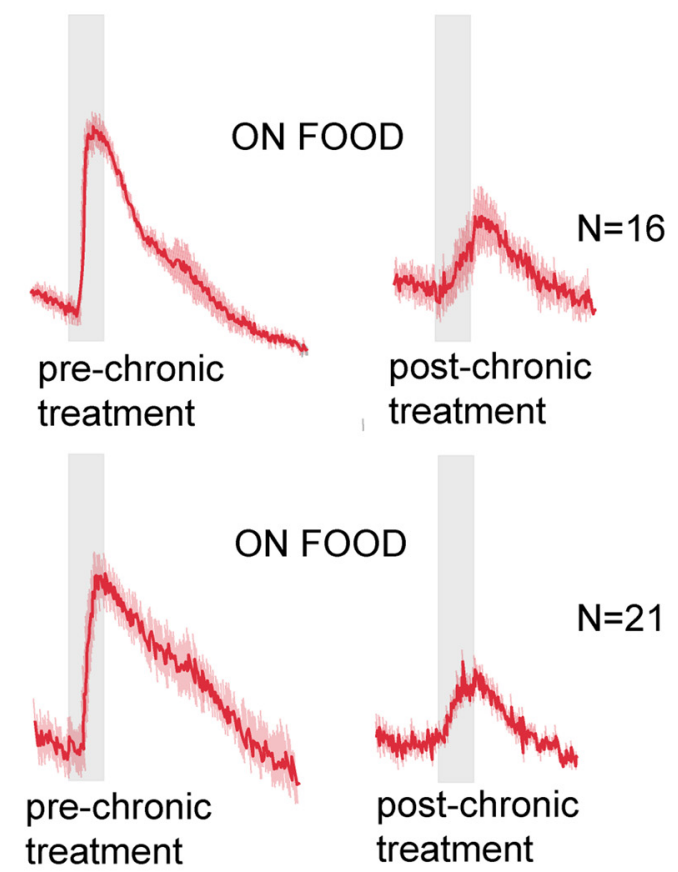

D

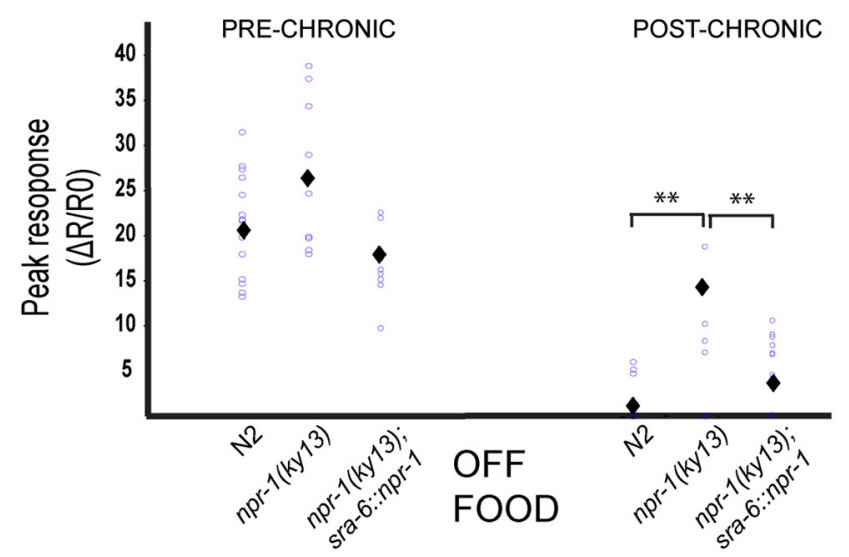

$\mathbf{E}$

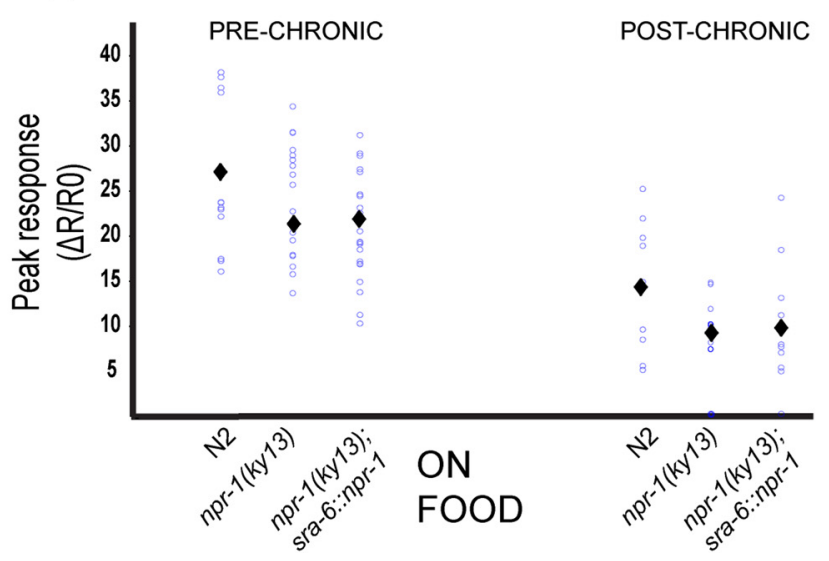

Figure 2. The neuropeptide receptor NPR- 1 acts in ASH to increase adaptation to repellents off food. $\boldsymbol{A}$ - $\boldsymbol{C}$, Average neuronal responses in ASH before and after chronic treatment with $10 \mathrm{~mm} \mathrm{CuCl} 2$. Shown are responses on and off food. Gray bars indicate the duration of the stimulus. $A$, Off food, wild type completely adapts after the chronic treatment and shows no postchronic responses. On food, wild type still responds after the chronic treatment. $\boldsymbol{B}, n p r-1(\mathrm{ky} 13)$ shows postchronic responses both off and on food. $\boldsymbol{C}$, Transgenic animals expressing genomic npr-1 DNA under the sra-6 promoter display wild-type responses. Data from one stable transgenic strain are shown. D, E, Quantification of ASH responses on and off food in wild-type, $n p r-1(k y 13)$, and rescued animals before and after chronic treatment. Blue circles represent individual animals assayed. Black diamonds indicate average value. $\boldsymbol{D}$, Postchronic responses in $n p r-1$ (ky13) are significantly larger than in wild-type and rescued animals off food. $\boldsymbol{E}$, Postchronic responses are not significantly different on food. Data were analyzed using the Mann-Whitney rank-sum test. ${ }^{*} p<0.05,{ }^{* *} p<0.01,{ }^{* * *} p<0.001$. 
A

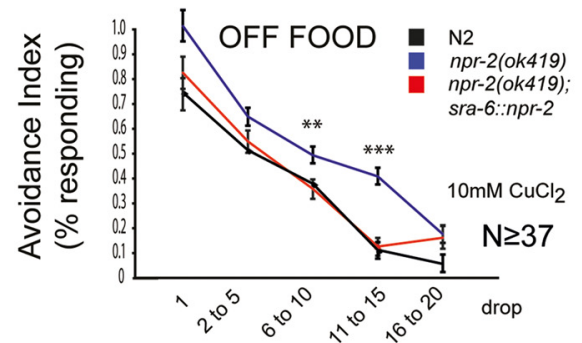

C

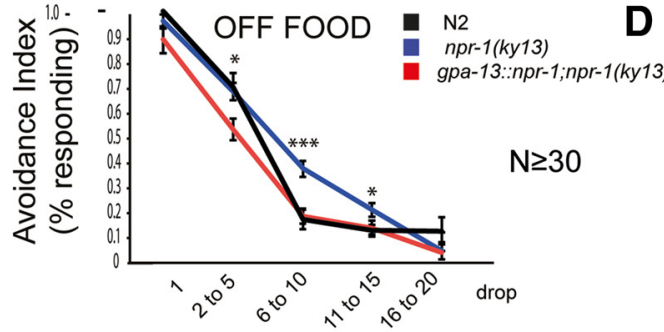

E wildtype

npr-2(ok419)
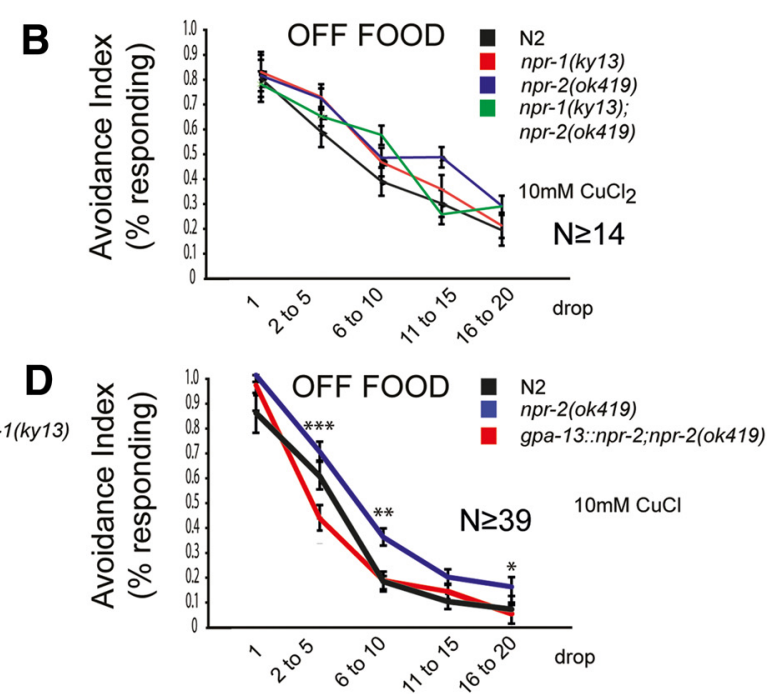

npr-2(ok419);
sra-6::npr-2

npr-1(ky13);

npr-2(ok419)

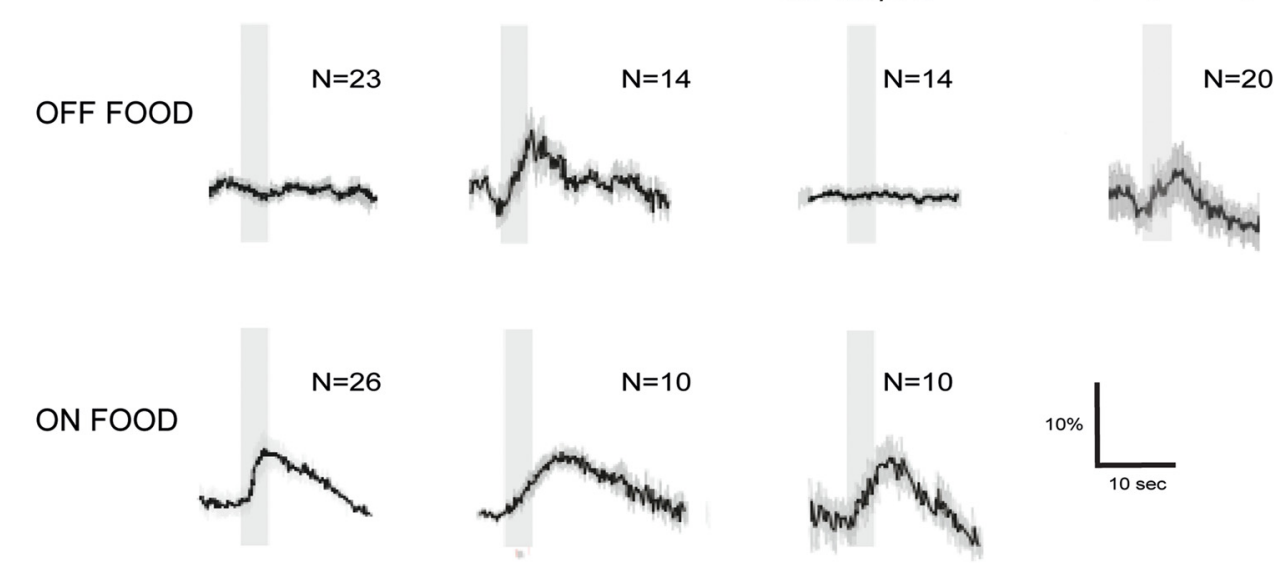

F

Pre-chronic

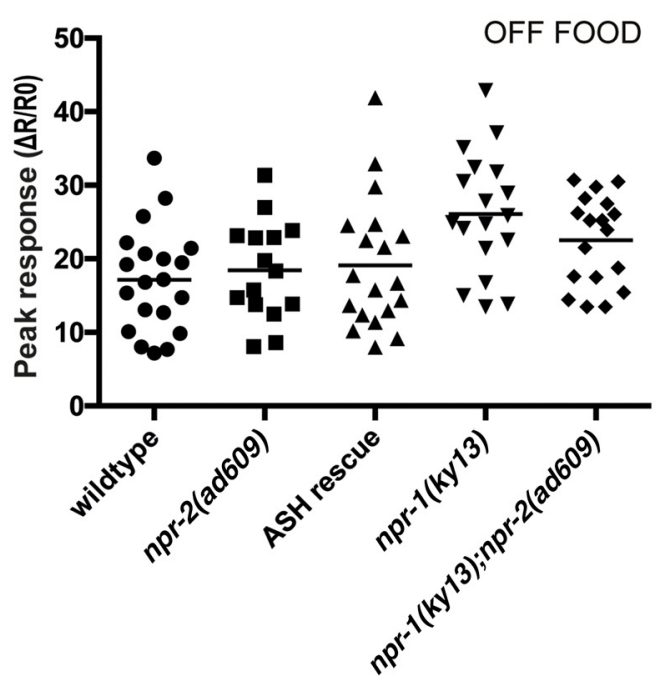

G

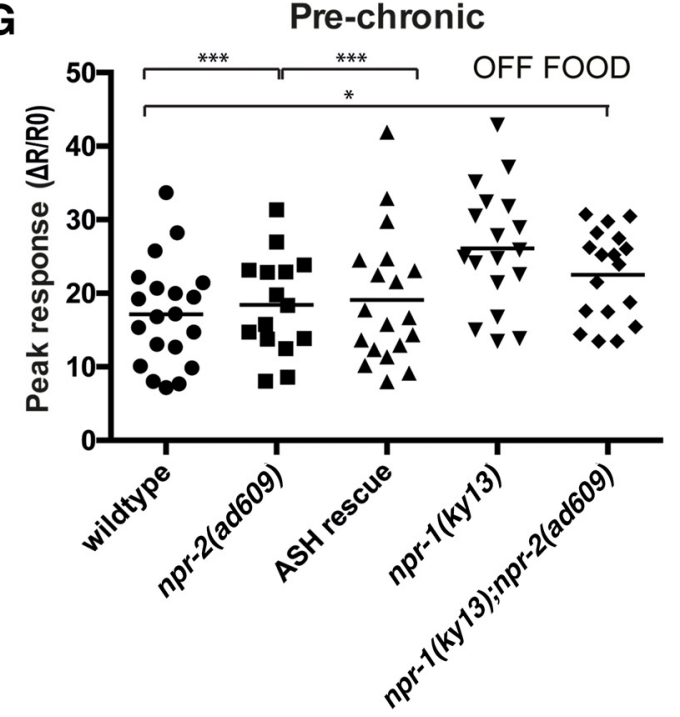

Figure 3. The neuropeptide receptor NPR-2 acts in ASH to increase adaptation in the absence of food. $\boldsymbol{A}-\boldsymbol{D}$, Fraction of animals responding to repeated drops of chemical repellent. For transgenic strains, the average values of two stable independent strains are shown. $A, n p r-2(0 k 419)$ adapts slower than wild type to $10 \mathrm{~mm} \mathrm{CuCl}_{2}$ off food. Transgenic animals expressing npr-2 CDNA under the sra-6 promoter (ASH, ASI, and PVQ) adapt like wild type. B, npr-1(ky13);npr-2(ok419) adapts like the npr-1(ky13) and npr-2(ok419) single mutants. C, Transgenic animals expressing genomic npr-1 DNA under the gpa-13 promoter display wild-type responses. $\boldsymbol{D}$, Transgenic animals expressing npr-2 CDNA under the gpa-13 promoter display wild-type responses. For transgenic strains, the average values of two independent strains are shown. $\boldsymbol{E}$, Average neuronal responses in $\mathrm{ASH}$ after chronic treatment with $10 \mathrm{~mm} \mathrm{CuCl}_{2}$. Shown are responses on and off food. Gray bars indicate the duration of the stimulus. Off food, wild type completely adapts after the chronic treatment and shows no postchronic responses. On food, wild type still responds after the chronic treatment. $n p r-2$ (ok419) shows postchronic responses both off and on food. Transgenic animals expressing npr-2 cDNA under the sra-6 promoter display wild-type responses. (Figure legend continues.) 

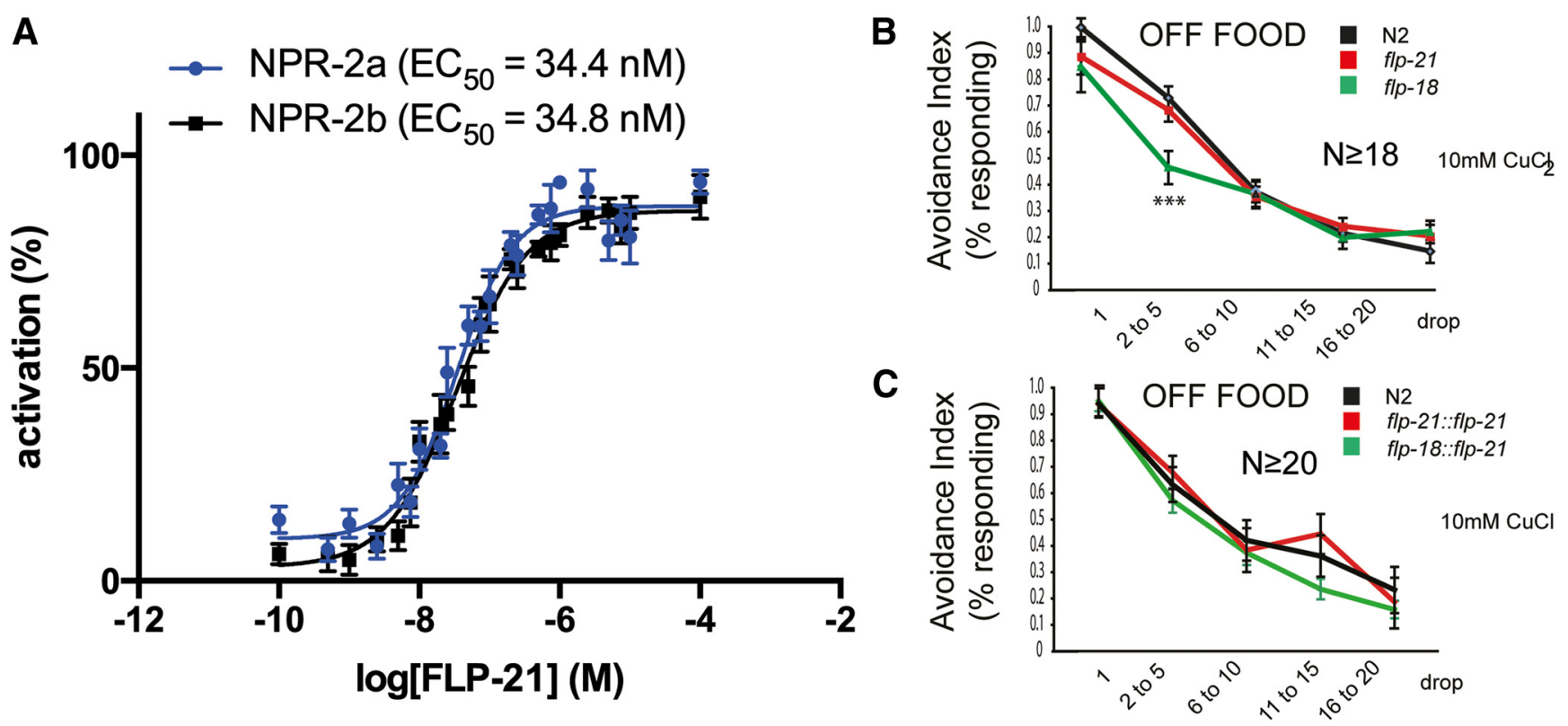

Figure 4. FLP-21 peptides are ligands for NPR-2. A, Concentration-dependent calcium responses evoked by FLP-21 (GLGPRPLRFamide) in CH0 cells expressing NPR-2a or NPR-2b. The log(EC ${ }_{50}$ ) values \pm SEM of FLP-21 is $-7.464 \pm 0.147$ for NPR-2a and $-7.459 \pm 0.110$ for NPR-2b. Each point \pm SEM represents the average of two independent experiments performed in triplicate. Concentration-response data are shown as relative (percentage) to the highest value (100\% activation) after normalization to the total calcium response $(n \geq 6)$. $\boldsymbol{B}, \boldsymbol{C}$, Fraction of animals responding to repeated drops of chemical repellent. $f l p-21(0 k 889)$ adapts like wild type and flp-18(db99) adapts faster than wild type (B) to $10 \mathrm{~mm} \mathrm{CuCl}_{2}$ off food. For transgenic strains, the average values of two independent strains are shown. Behavioral data were analyzed using Student's $t$ test. ${ }^{*} p<0.05,{ }^{* *} p<0.01,{ }^{* * *} p<0.001$.

sra-6 or gpa-13 promoter and found that the behavioral and calcium imaging adaptation phenotypes of npr-2(ok419) were rescued (Fig. 3A,C,E,F). This suggests that both NPR-1 and NPR-2 act in the ASH neuron to increase adaptation in the absence of food.

NPR-1 and NPR-2 could either be acting in parallel, separate pathways to modulate cellular responses in ASH or in the same signaling pathway. We performed behavioral tests and calcium imaging experiments, which showed that double mutants carrying both the npr-1(ky13) and npr-2(ok419) mutations do not have a stronger defect than the single npr-1(ky13) and npr2(ok419) mutants (Fig. $3 B, E-G$ ). These results suggest that NPR-1 and NPR-2 act in the same pathway to increase ASH adaptation.

\section{The NPR-1 ligands FLP-18 and FLP-21 do not increase ASH adaptation}

To identify relevant neuropeptide receptor ligands, we surveyed known C. elegans neuropeptides using in vivo and in vitro approaches. Previous in vitro studies have identified the FMRFamide peptides FLP-18 and FLP-21 as ligands of NPR-1 (Rogers et al., 2003), suggesting that these peptides could be functioning to increase adaptation through NPR-1. We performed similar in vitro screens for NPR-2 ligands, testing $>260$ known C. elegans

\section{$\leftarrow$}

(Figure legend continued.) Off food, npr-1(ky13);npr-2(ok419) has similar postchronic responses to the npr-1(ky13) and npr-2(ok419) single mutants. F, G, Quantification of ASH responses off food before and after chronic treatment. Black triangles represent individual animals assayed. Straight lines indicate average value. $\boldsymbol{F}$, Prechronic responses off food are similar in all genotypes. G, Postchronic responses are significantly larger in npr-2(ok419) than in wild type. Transgenic animals expressing npr-2 CDNA under the sra- 6 promoter display wildtype responses off food. Data from one stable transgenic strain are shown. Behavioral data were analyzed using Student's $t$ test. Calcium imaging data were analyzed using the Mann-Whitney rank-sum test. ${ }^{*} p<0.05,{ }^{* *} p<0.01,{ }^{* * *} p<0.001$. neuropeptides for activation of the two NPR-2 isoforms, NPR-2a and NPR-2b. Only one peptide encoded by flp-21 (GLGPRPLRFamide) showed evidence for activating NPR-2 at physiological concentrations (Fig. 4A). Thus, the FLP-21 neuropeptide appears to be a ligand of NPR-2, as well as of NPR-1.

Therefore, we tested null mutants for $f l p-21$ and $f l p-18$ for ASH adaptation phenotypes. We found that $f l p-21$ (ok889) adapts like wild type and that $f l p-18(\mathrm{db99})$ adapts more rapidly (Fig. $4 B$ ), indicating that the peptides encoded by these genes are not required for adaptation in ASH. To test whether these previously identified NPR-1 ligands might act redundantly with other peptides, we also made lines overexpressing $f l p-18$ and $f l p-21$ in wildtype background. None of these lines displayed altered responses to acute or repeated repellent stimulation (Fig. 4C). Thus, FLP-21 and FLP-18 peptides do not appear to be necessary for activating NPR-1 or NPR-2 in ASH. We also tested deletion mutants of other FMRFamide-related peptide genes ( $f l p-1-f l p-3, f l p-6-f l p$ 13, $f l p-15-f l p-17, f l p-19, f l p-20, f l p-25, f l p-28$, and $f l p-33)$ and found that none of these strains exhibit an adaptation defect similar to $n p r-1$ and npr-2 (data not shown). Together, these results suggest that the relevant ligand (or ligands) that activates NPR-1 and NPR-2 to promote ASH adaptation is likely to be an unknown peptide or that a more complex network of peptidergic interactions is at play.

\section{Neuropeptide signaling mediates the effect of dopamine on adaptation}

NPR-1 and dopamine signaling have opposing effects on adaptation to repellents: NPR-1 increases adaptation in unfed animals, whereas dopamine decreases adaptation in well fed animals. We showed previously that cat-2(e1112) animals, which carry a nonsense allele in the gene encoding tyramine hydroxylase and are defective in dopamine biosynthesis (Lints and Emmons, 1999), adapted rapidly in the presence of food, suggesting that endoge- 
A

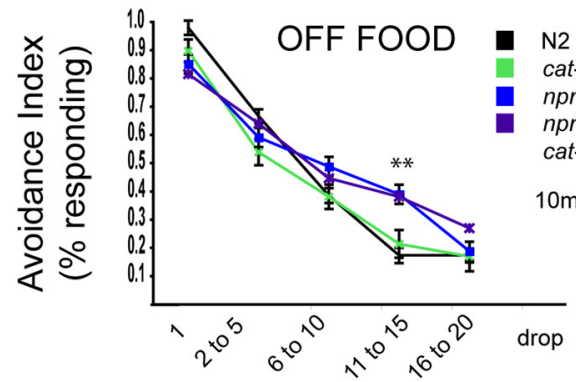

N2

eat-2(e1112)

$n p r-1(k y 13)$

$n p r-1(k y 13)$

cat-2(e1112)

$\mathrm{OmM} \mathrm{CuCl}_{2}$

$\mathrm{N} \geq 18$

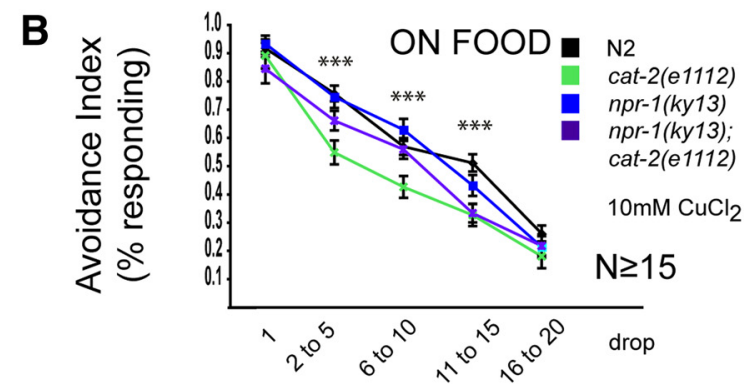

C

OFF FOOD

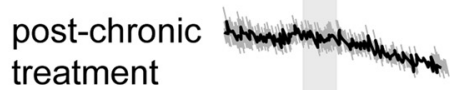

$10 \mathrm{mM} \mathrm{CuCl}_{2}$

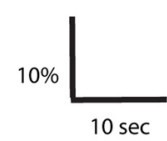

10 sec

cat-2(e1112)

N2
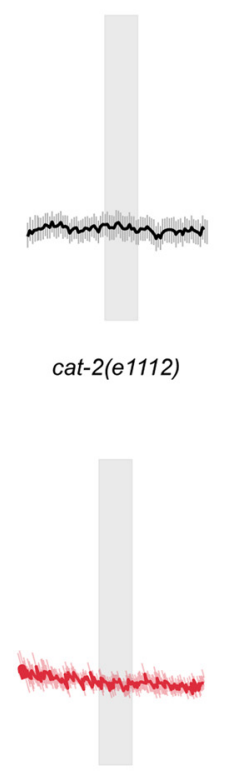

cat-2(e1112)

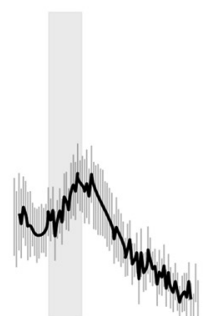

npr-1(ky13)

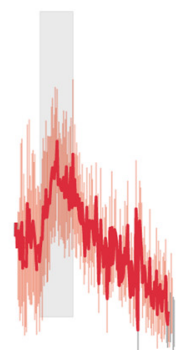

npr-1(ky13)

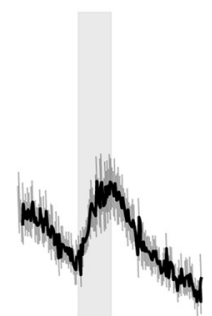

cat-2(e1112) $n p r-1(k y 13)$

D

\section{ON FOOD \\ post-chronic treatment}

N2

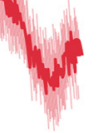

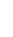


A

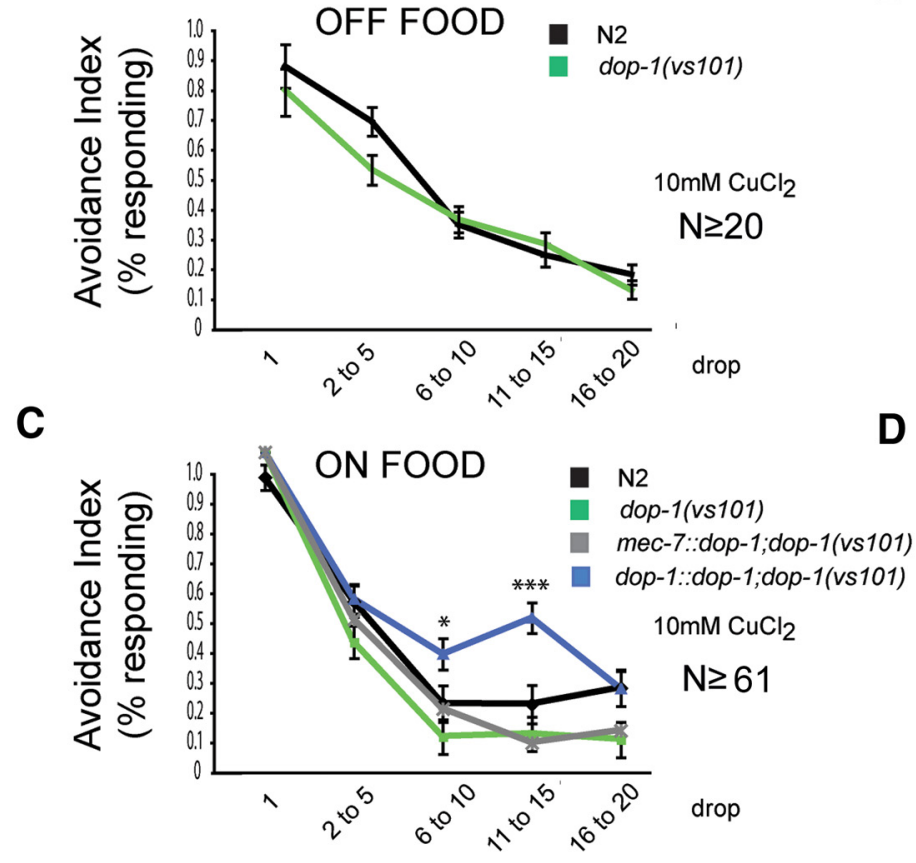

B
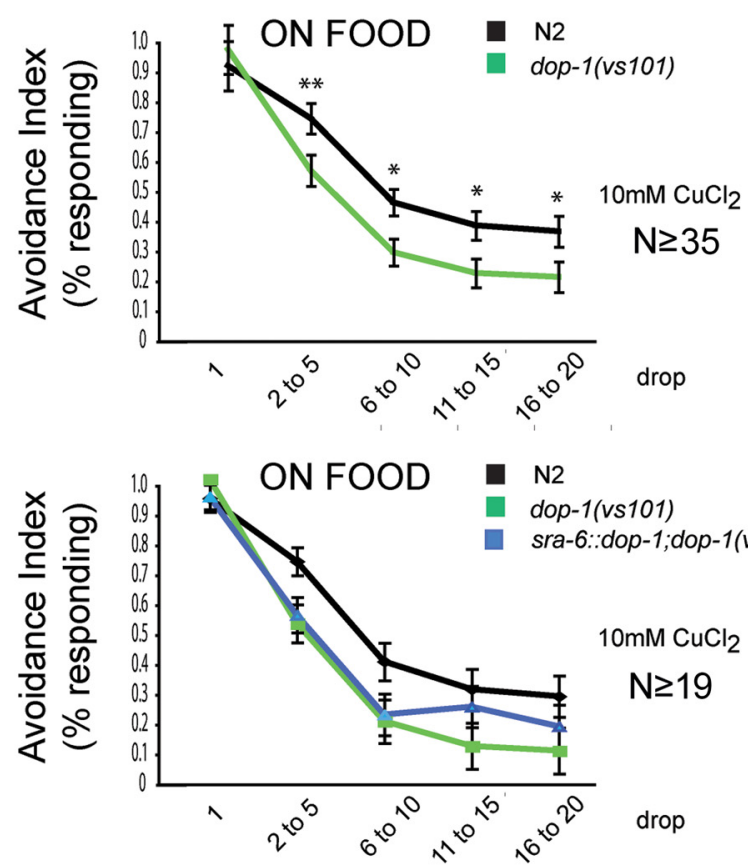

Figure 6. The dopamine receptor D0P-1 inhibits adaptation on food. $\boldsymbol{A}-\boldsymbol{D}$, Fraction of animals responding to repeated drops of $10 \mathrm{~mm}$ CuCl 2 . $\boldsymbol{A}$, dop- 1 (vs 101$)$ adapts like wild-type off food. $\boldsymbol{B}$, dop-1(vs101) adapts faster than wild type on food. $\boldsymbol{C}$, Rescue of dop-1 using the dop-1 promoter rescues the dop- 1 phenotype, but expression under the mec-7 promoter does not. $\boldsymbol{D}$, Rescue of dop-1 using the sra-6 promoter does not rescue the phenotype. Behavioral data were analyzed using Student's $t$ test. ${ }^{*} p<0.05,{ }^{* *} p<0.01$, ${ }^{* * *} p<0.001$. For transgenic strains, the average values of two independent strains are shown.

nous dopamine is required for the inhibitory effect of food on adaptation (Ezcurra et al., 2011).

To determine how these opposite pathways interact, we analyzed copper adaptation in cat-2; npr-1 double mutants. In the absence of food, in both behavioral and calcium imaging experiments, we found that cat-2; npr-1 animals showed decreased adaptation compared with wild type (Fig. $5 A, C, E$ ), a phenotype comparable with that of the $n p r-1$ single mutant. Likewise, in the presence of food, cat-2; npr-1 animals showed slow adaptation (Fig. $5 B, D, F$ ), resembling wild type and the $n p r-1$ single mutant, but not the cat- 2 single mutant. Thus, $n p r-1$ appeared completely epistatic to cat-2 with respect to ASH adaptation phenotypes. These results indicate that dopamine acts in the same pathway as NPR-1 to inhibit ASH adaptation and imply that dopamine somehow inhibits NPR-1 activity. Because NPR-1 is a neuropeptide receptor, this suggests that the effects of dopamine on adaptation could be mediated indirectly through changes in neuropeptide signaling.

\section{Dopamine inhibits adaptation through the dopamine receptor DOP-1}

To learn more about the role of dopamine in ASH adaptation, we analyzed the repellent adaptation phenotypes of dopamine receptor mutants. C. elegans has four G-protein-coupled dopamine receptors, $d o p-1$ to $d o p-4$, and we tested deletion mutants of each for food-dependent abnormalities in copper adaptation. Previously, we showed that DOP-4 is required for the acute response but not for adaptation in ASH in the presence of food (Ezcurra et al., 2011). We found that the dop-1(vs101) deletion allele has an adaptation phenotype identical to cat-2: mutant animals adapt faster than wild type on food, but not off food (Fig. 6A,B), This result suggested that DOP- 1 acts in the presence of food to inhibit adaptation.
To determine whether DOP-1 acts cell autonomously in ASH to modulate adaptation to repellents, we tested whether the dop-1 mutant phenotype could be rescued by expressing a dop-1(+) transgene in ASH. We observed that an ASHexpressing sra-6::dop-1 transgene failed to rescue the $d o p-1$ adaptation phenotype (Fig. 6D); in contrast, expression of dop-1 under its own promoter rescued the adaptation phenotype (Fig. 5C). Thus, we reasoned that DOP-1 might function in neurons extrinsic to ASH, perhaps to control release of NPR-1 ligands.

DOP-1 has been reported to be expressed in a subset of neurons, including the ALM, AVM, and PLM gentle touch neurons, cholinergic motor neurons in the ventral cord, and the RIS, RIM, AUA, RIB, PHC, and PVQ interneurons (Tsalik et al., 2003; Chase et al., 2004; Sanyal et al., 2004). Expressing dop-1(+) under a touch neuron-specific promoter, mec-7 (shown previously to rescue mechanosensory adaptation phenotypes; Kindt et al., 2007) failed to rescue the copper adaptation phenotype of dop-1 (Fig. 6C), but expressing $d o p-1(+)$ under the $f l p-8$ promoter, which expresses in the touch neurons as well as several additional neuron classes, fully rescued the dop-1 adaptation phenotype (Fig. 7A). We also generated cell-specific RNAi lines expressing $d o p-1$ sense and antisense sequences under the $f l p-8$ promoter (referred to as dop-1 RNAi), along with control RNAi lines expressing the same $d o p-1$ sequences under the $d o p-1$ promoter. Behavioral phenotyping revealed that expression of $d o p-1$ RNAi under the $d o p-1$ and $f l p-8$ promoters leads to increased adaptation on food compared with wild type (Fig. $7 B, C$ ). One candidate site for DOP-1 function are the AUA neurons, because they are in the expression domains of $d o p-1$ and $f l p-8$ but not mec-7. To determine whether DOP-1 expression in AUA is required for modulation of adaptation, we constructed a dop-1 rescue strain using the C41G7.6 promoter, which only overlaps with $f l p-8$ and 

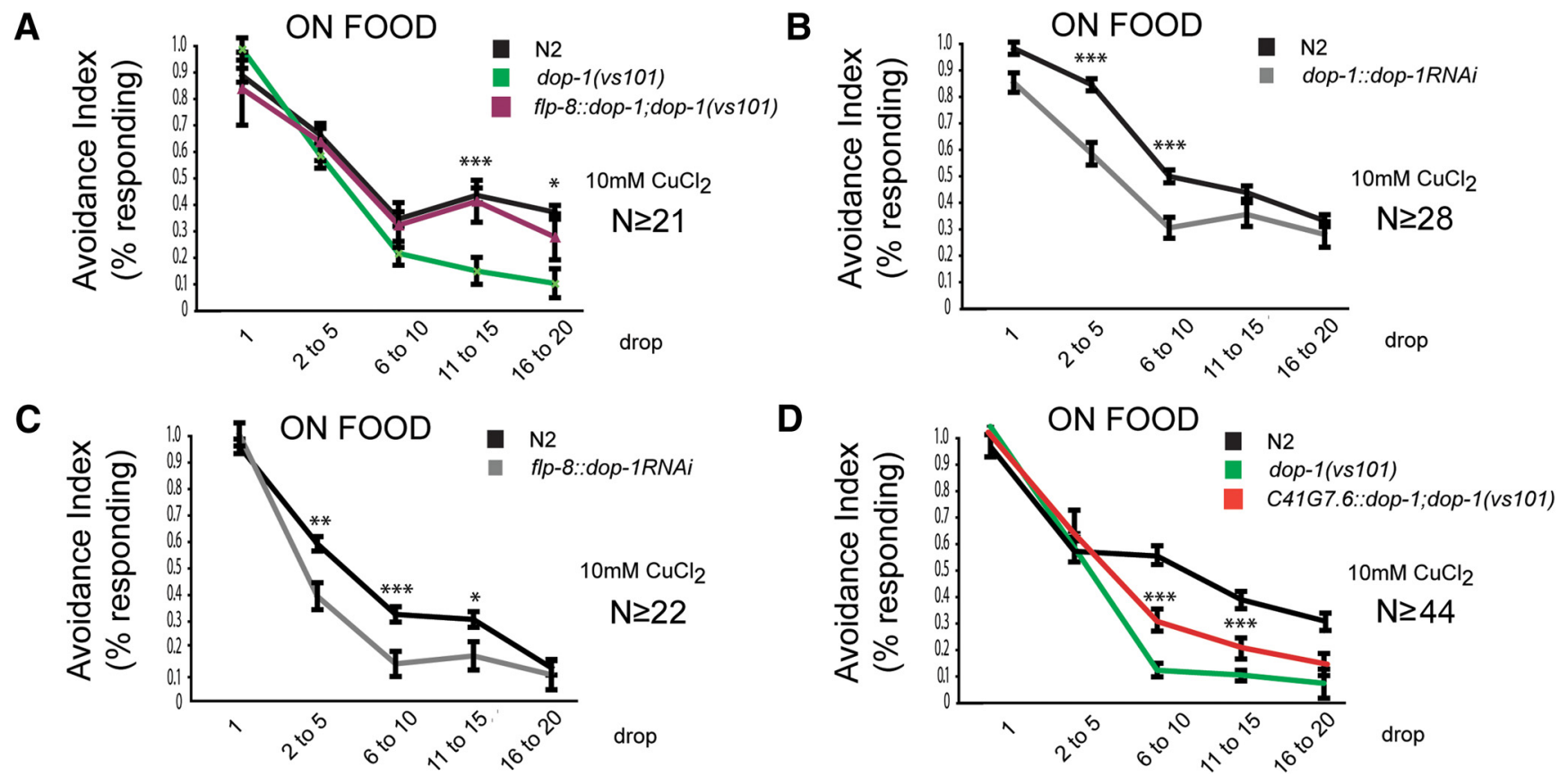

Figure 7. DOP-1 acts in FLP-8-expressing neurons to inhibit adaptation on food. $A-D$, Fraction of animals responding to repeated drops of $10 \mathrm{~mm} \mathrm{CuCl}_{2}$. A, Rescue of dop-1 using the flp-8 promoter rescues the adaptation phenotype on food. $\boldsymbol{B}$, Knockdown of dop- 7 in dop-1-expressing neurons increases adaptation on food. $C$, Knockdown of dop- 7 in flp-8-expressing neurons increases adaptation on food. $\boldsymbol{D}$, Rescue of dop-1 using the (41G7.6 promoter rescues the adaptation phenotype on food. For transgenic strains, the average values of two independent strains are shown. Behavioral data were analyzed using Student's $t$ test. ${ }^{*} p<0.05,{ }^{* *} p<0.01,{ }^{* * *} p<0.001$. For transgenic strains, the average values of two independent strains are shown.
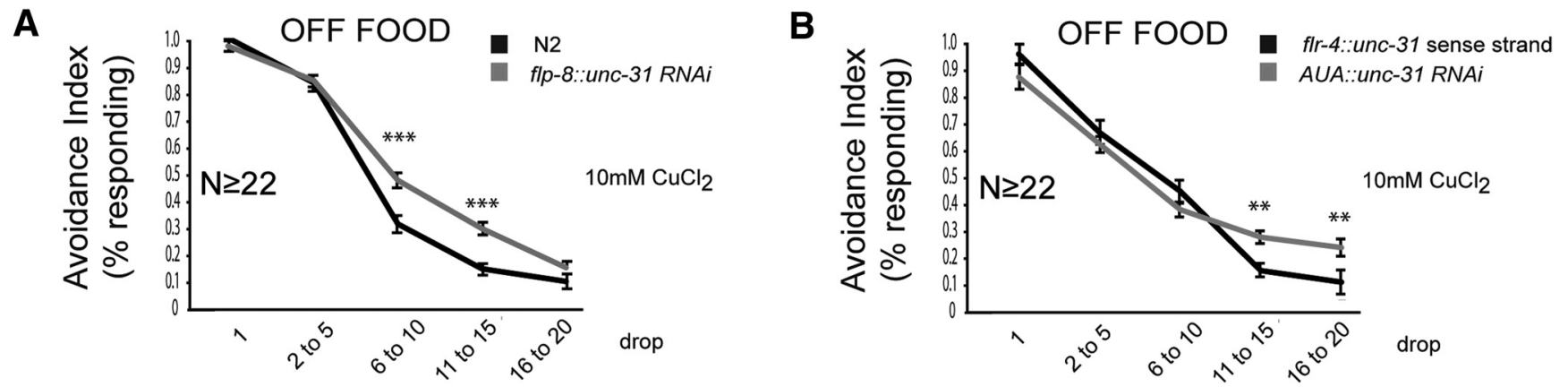

Figure 8. Neuropeptide release from AUA increases adaptation. $\boldsymbol{A}, \boldsymbol{B}$, Fraction of animals responding to repeated drops of $10 \mathrm{~mm} \mathrm{CuCl}_{2} \cdot \boldsymbol{A}, \mathrm{Knockdown}$ of unc-31 RNAi in flp-8-expressing neurons suppresses adaptation. $\boldsymbol{B}$, Knockdown of unc-31 RNAi in AUA suppresses adaptation. Behavioral data were analyzed using Student's $t$ test. ${ }^{* *} p<0.01,{ }^{* * *} p<0.001$. For transgenic strains, the average values of two independent strains are shown.

dop-1 in AUA. Driving expression of dop-1 under C41G7.6 rescued the adaptation phenotype (Fig. 7D), suggesting that DOP-1 acts in the AUA neurons to decrease ASH adaptation in the presence of food, potentially by negatively regulating the release of neuropeptides that act through the NPR-1 pathway.

\section{Neuropeptide release from AUA increases adaptation}

We then tested whether neuropeptide release from flp-8expressing neurons suppresses adaptation. unc-31 encodes the dense-core vesicle priming proteins CAPS, which is essential for the release of dense core vesicles (Hammarlund et al., 2008; Speese et al., 2007). Expression of unc-31 RNAi under the flp- 8 promoter suppressed adaptation (Fig. $8 A$ ), suggesting that peptidergic signaling from $f l p$ - 8 -expressing neurons function to increase adaptation. To determine whether neuropeptide signaling from AUA specifically is required for modulation of adaptation, we constructed a strain expressing unc-31 RNAi in AUA only, by expressing the sense strand under the $f l p-8$ promoter and the antisense strand under the flr-4 promoter. These two promoters overlap in AUA but not in other neurons, resulting in expression of double-stranded $u n c-31$ RNAi specifically in AUA. This transgene resulted in decreased adaptation compared with the unc-31 sense strand alone expressed under the flr-4 promoter (Fig. $8 B$ ), suggesting that peptidergic signaling from AUA results in increased adaptation and in line with DOP-1 acting in AUA to negatively regulate neuropeptide release.

\section{Discussion}

We have shown here that sensory adaptation of the ASH nociceptors to soluble repellents is controlled by different fooddependent neuromodulatory pathways. In the presence of food, dopamine acts via the $\mathrm{D}_{1}$-like receptor DOP-1 to inhibit adaptation, whereas in the absence of food, neuropeptides act through the NPY-like receptor NPR-1 to increase adaptation. These pathways are not independent; rather, dopamine modulation of adaptation is dependent on the cell-autonomous activity of NPR-1 


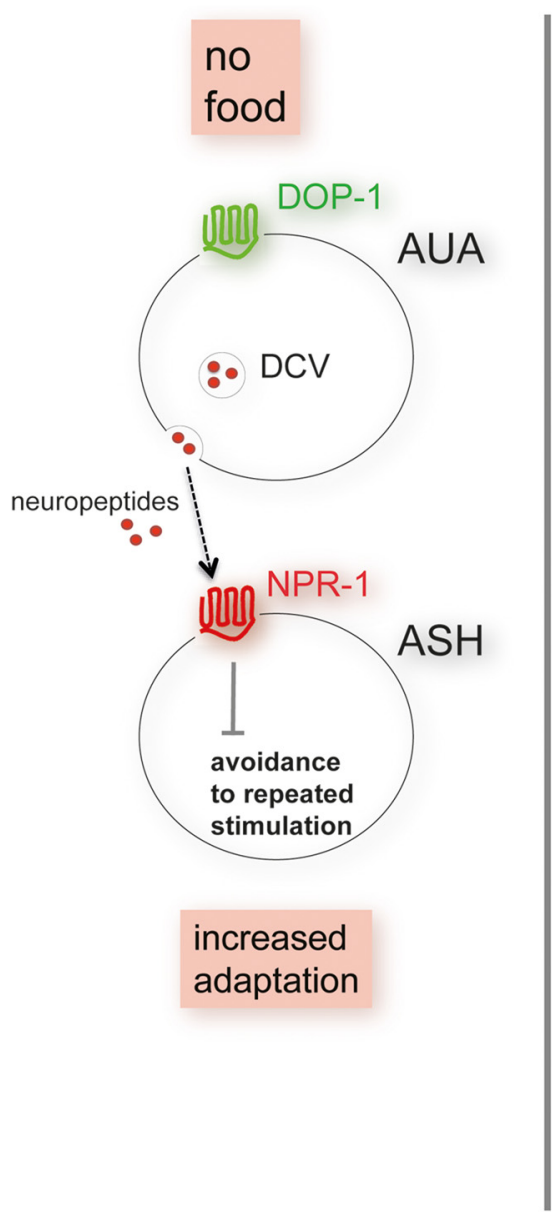

Figure 9. Proposed model for modulation of avoidance on and offfood. In the presence of food (right), dopamine acts via DOP-1 to inhibit neuropeptide release from AUA, resulting in low activity of NPR-1 in ASH and allowing ASH to continuously respond to repeated stimulation. In the absence of food (left), DOP-1 is not activated by dopamine, resulting in the release of dense-core vesicles from AUA. Neuropeptides of unknown identity act directly or indirectly to activate NPR-1, which inhibits ASH responses to continued stimulation, resulting in adaptation.

in the ASH neurons. Because both DOP-1 activity and neuropeptide release are both required for the adaptation phenotype in the presence of food and both appear to function cell specifically in AUA, we conclude that dopamine acts via DOP-1 to negatively regulate the release of neuropeptides from the AUA interneurons (Fig. 9). In addition to NPR-1, another neuropeptide receptor, NPR-2, also increases adaptation in the absence of food. NPR-1 and NPR-2 are not independent and act in the same pathway to increase ASH adaptation. Thus, the control of food-dependent behavioral states appears to involve a cascade of neuromodulatory peptides and amines that modifies the properties of target neurons such as ASH.

We have shown previously that dopamine has at least two food-related effects on ASH chemosensation: it enhances acute responses to repellents and decreases sensory adaptation (Ezcurra et al., 2011). The effect on acute responses requires the activity of the DOP-4 receptor in the ASH neurons themselves, implying that it is a direct consequence of modulation of the ASH neurons by dopamine. In contrast, because $n p r-1$ is epistatic to dopamine signaling genes with respect to adaptation, the effect of dopamine on adaptation appears to occur through indirect inhibition of an "off-food" neuropeptide signal.

Interactions between neuromodulator systems play a critical role in the control of behavioral states in many organisms, in- cluding mammals. In C. elegans, dopamine has been shown to negatively regulate release of octopamine from neurons controlling CREB-dependent gene expression in interneurons (Suo et al., 2006), a process implicated in the response to starvation. Likewise, octopamine acts via the SER-6 receptor to promote the release of peptides that antagonize avoidance responses to octanol (Mills et al., 2012). Finally, under hypoxic conditions, serotonin acts via the SER-7 receptor to promote the release of the NPR-1 ligand FLP-21, thereby enhancing soluble chemotaxis (Pocock and Hobert, 2010). Future studies of these processes in C. elegans may provide insight into conserved mechanisms by which feeding state modifies neural circuits controlling complex behaviors.

This study is not the first to implicate the NPR-1 receptor in the modulation of neuronal activity in response to feeding state. $n p r-1$ was first defined genetically because of its role in aggregation, a behavior strongly influenced by feeding state (de Bono and Bargmann, 1998). npr-1 has been shown subsequently to affect other behaviors directly related to feeding, such as dispersal on a bacterial lawn (GloriaSoria and Azevedo, 2008), food leaving (Milward et al., 2011), and avoidance of pathogenic bacteria (Styer et al., 2008; Reddy et al., 2009). Interestingly, for these other behaviors, the phenotype of the N2 allele $215 \mathrm{~V}$, a gain-of-function variant that arose during cultivation in the laboratory (McGrath et al., 2009), differs from both null alleles and the naturally occurring $215 \mathrm{~F}$ allele. In contrast, we observed that both $n p r-1(215 \mathrm{~V})$ and $n p r-1(215 F)$ strains showed "wild-type" adaptation to copper in the absence of food, whereas npr-1 nulls showed abnormal adaptation. Thus, our results indicate that the naturally occurring form of NPR-1 as well as the laboratory-selected form are involved in feeding state-dependent modulation of the ASH neurons. Because NPR-1 shows a high degree of sequence similarity to mammalian NPY receptors, this may suggest a deeply conserved role for these receptors in the control of feeding-related behavioral states. NPR-1 and NPR-2 have been implicated in avoidance responses to methyl salicylate (Luo et al. 2015) but act in a different set of neurons to mediate these responses, suggesting a complex role for these neuropeptide receptors in mediating responses to different noxious stimuli through different neurons.

Our data suggest a model by which dopaminergic signaling regulates neuropeptide signaling to modulate aversive behaviors depending on the feeding state of the animal. Rescue and RNAi data suggest that the AUA neurons act as candidate cells linking dopaminergic and neuropeptide signaling, and we speculate that activation of DOP-1 in these cells results in the inhibition of neuropeptide release. The relevant peptides whose release from AUA might modulate ASH are currently undetermined. The known NPR-1 and NPR-2 ligands FLP-18 and FLP-21 are not required to increase adaptation, suggesting that other peptide 
ligands may function as NPR-1 and/or NPR-2 ligands to modulate adaption in ASH. Alternatively (or additionally), a more complex network of peptidergic interactions may be involved. Both flp-21- and flp-18-encoded peptides are known to act on multiple receptors in addition to NPR-1 and NPR-2, and several of these target receptors are known to have additional ligands (Peymen et al., 2014). In such a network of complex and overlapping ligand-receptor interactions, individual ligand knock-outs might not be expected to phenocopy knock-outs of individual targets. Moreover, if NPR-1 and NPR-2 function as a dimer (a possibility consistent with our double-mutant analysis), the heteromeric receptor might have distinct signaling properties from either homomeric receptor. Future genetic and biochemical studies may allow us to address these possibilities.

According to the C. elegans wiring diagram, there are no synaptic connections between the dopamine neurons and AUA, nor between AUA and ASH. Thus, our model implies that a sequence of extrasynaptic modulatory connections in the C. elegans nervous system are involved in signaling food availability. Many other examples of amine and neuropeptide signaling in C. elegans (Chase et al., 2004; Kindt et al., 2007; Ezak and Ferkey, 2010; Ezcurra et al., 2011) and mammals (Agnati et al., 1986; Marcellino et al., 2012) are known or suspected to occur extrasynaptically. Thus, neuromodulator signaling forms a wireless network overlaid on the synaptic wiring diagram that is particularly critical for the control of behavioral states.

\section{References}

Agnati LF, Fuxe K, Zoli M, Ozini I, Toffano G, Ferraguti F (1986) A correlation analysis of the regional distribution of central enkephalin and betaendorphin immunoreactive terminals and of opiate receptors in adult and old male rats. Evidence for the existence of two main types of communication in the central nervous system: the volume transmission and the wiring transmission. Acta Physiol Scand 128:201-207. CrossRef Medline

Alkema MJ, Hunter-Ensor M, Ringstad N, Horvitz HR (2005) Tyramine functions independently of octopamine in the Caenorhabditis elegans nervous system. Neuron 46:247-260. CrossRef Medline

Avery L, Thomas JH (1997) Feeding and defecation. In: C. elegans II (Riddle DL, Blumenthal T, Meyer BJ, Priess JR, eds). Cold Spring Harbor, NY: Cold Spring Harbor Laboratory.

Brenner S (1974) The genetics of Caenorhabditis elegans. Genetics 77:71-94. Medline

Chase DL, Pepper JS, Koelle MR (2004) Mechanism of extrasynaptic dopamine signaling in Caenorhabditis elegans. Nat Neurosci 7:1096-1103. CrossRef Medline

Cohen M, Reale V, Olofsson B, Knights A, Evans P, de Bono M (2009) Coordinated regulation of foraging and metabolism in C. elegans by RFamide neuropeptide signaling. Cell Metab 9:375-385. CrossRef Medline

de Bono M, Bargmann CI (1998) Natural variation in a neuropeptide Y receptor homolog modifies social behavior and food response in C. elegans. Cell 94:679-689. CrossRef Medline

Esposito G, Di Schiavi E, Bergamasco C, Bazzicalupo P (2007) Efficient and cell specific knock-down of gene function in targeted C. elegans neurons. Gene 395:170-176. CrossRef Medline

Ezak MJ, Ferkey DM (2010) The C. elegans D2-like dopamine receptor DOP-3 decreases behavioral sensitivity to the olfactory stimulus 1-octanol. PLoS One 5:e9487. CrossRef Medline

Ezcurra M, Tanizawa Y, Swoboda P, Schafer WR (2011) Food sensitizes $C$. elegans avoidance behaviors through acute dopamine signaling. EMBO J 30:1110-1122. CrossRef Medline

Gloria-Soria A, Azevedo RB (2008) npr-1 Regulates foraging and dispersal strategies in Caenorhabditis elegans. Curr Biol 18:1694-1699. CrossRef Medline

Hamakawa M, Uozumi T, Ueda N, Iino Y, Hirotsu T (2015) A role for Ras in inhibiting circular foraging behavior as revealed by a new method for time and cell-specific RNAi. BMC Biol 13:6. CrossRef Medline

Hammarlund M, Watanabe S, Schuske K, Jorgensen EM (2008) CAPS and syntaxin dock dense core vesicles to the plasma membrane in neurons. J Cell Biol 180:483-491. CrossRef Medline

Harris GP, Hapiak VM, Wragg RT, Miller SB, Hughes LJ, Hobson RJ, Steven R, Bamber B, Komuniecki RW (2009) Three distinct amine receptors operating at different levels within the locomotory circuit are each essential for the serotonergic modulation of chemosensation in Caenorhabditis elegans. J Neurosci 29:1446-1456. CrossRef Medline

Harris G, Mills H, Wragg R, Hapiak V, Castelletto M, Korchnak A, Komuniecki RW (2010) The monoaminergic modulation of sensory-mediated aversive responses in Caenorhabditis elegans requires glutamatergic/peptidergic cotransmission. J Neurosci 30:7889-7899. CrossRef Medline

Hilliard MA, Bargmann CI, Bazzicalupo P (2002) C. elegans responds to chemical repellents by integrating sensory inputs from the head and the tail. Curr Biol 12:730-734. CrossRef Medline

Hilliard MA, Apicella AJ, Kerr R, Suzuki H, Bazzicalupo P, Schafer WR (2005) In vivo imaging of C. elegans ASH neurons: cellular response and adaptation to chemical repellents. EMBO J 24:63-72. CrossRef Medline

Hills T, Brockie PJ, Maricq AV (2004) Dopamine and glutamate control area-restricted search behavior in Caenorhabditis elegans. J Neurosci 24: 1217-1225. CrossRef Medline

Hobert O (2002) PCR fusion-based approach to create reporter gene constructs for expression analysis in transgenic C. elegans. Biotechniques 32: 728-730. Medline

Horvitz HR, Chalfie M, Trent C, Sulston JE, Evans PD (1982) Serotonin and octopamine in the nematode Caenorhabditis elegans. Science 216:10121014. CrossRef Medline

Hukema RK, Rademakers S, Jansen G (2008) Gustatory plasticity in C. elegans involves integration of negative cues and $\mathrm{NaCl}$ taste mediated by serotonin, dopamine, and glutamate. Learn Mem 15:829-836. CrossRef Medline

Janssen T, Meelkop E, Lindemans M, Verstraelen K, Husson SJ, Temmerman L, Nachman RJ, Schoofs L (2008) Discovery of a cholecystokinin-gastrin-like signaling system in sematodes. Endocrinology 149:2826-2839. CrossRef Medline

Kerr R, Lev-Ram V, Baird G, Vincent P, Tsien RY, Schafer WR (2000) Optical imaging of calcium transients in neurons and pharyngeal muscle of C. elegans. Neuron 26:583-594. CrossRef Medline

Kindt KS, Quast KB, Giles AC, De S, Hendrey D, Nicastro I, Rankin CH, Schafer WR (2007) Dopamine mediates context-dependent modulation of sensory plasticity in C. elegans. Neuron 55:662-676. CrossRef Medline

Lints R, Emmons SW (1999) Patterning of dopaminergic neurotransmitter identity among Caenorhabditis elegans ray sensory neurons by a TGFB family signaling pathway and a Hox gene. Development 126:5819-5831. Medline

Li C, Kim K (2008) Neuropeptides. WormBook 1-36. CrossRef

Luo J, Xu Z, Tan Z, Zhang Z, Ma L (2015) Neuropeptide receptors NPR-1 and NPR-2 regulate Caenorhabditis elegans avoidance response to the plant stress hormone methyl salicylate. Genetics 199:523-531. CrossRef Medline

Marcellino D, Kehr J, Agnati LF, Fuxe K (2012) Increased affinity of dopamine for $\mathrm{D}(2)$-like versus $\mathrm{D}(1)$-like receptors. Relevance for volume transmission in interpreting PET findings. Synapse 66:196-203. CrossRef Medline

McGrath PT, Rockman MV, Zimmer M, Jang H, Macosko EZ, Kruglyak L, Bargmann CI (2009) Quantitative mapping of a digenic behavioral trait implicates globin variation in C. elegans sensory behaviors. Neuron 61: 692-699. CrossRef Medline

Mello CC, Kramer JM, Stinchcomb D, Ambros V (1991) Efficient gene transfer in C. elegans: extrachromosomal maintenance and integration of transforming sequences. EMBO J 10:3959-3970. Medline

Mills H, Wragg R, Hapiak V, Castelletto M, Zahratka J, Harris G, Summers P, Korchnak A, Law W, Bamber B, Komuniecki R (2012) Monoamines and neuropeptides interact to inhibit aversive behaviour in Caenorhabditis elegans. ЕMBO J 31:667-678. CrossRef Medline

Milward K, Busch KE, Murphy RJ, de Bono M, Olofsson B (2011) Neuronal and molecular substrates for optimal foraging in Caenorhabditis elegans. Proc Natl Acad Sci U S A 108:20672-20677. CrossRef Medline

Peymen K, Watteyne J, Frooninckx L, Schoofs L, Beets I (2014) The FMRFamide-like peptide family in nematodes. Front Endocrinol (Lausanne) [Erratum (2015) 9:120] 5:90. CrossRef Medline

Pocock R, Hobert O (2010) Hypoxia activates a latent circuit for processing 
gustatory information in C. elegans. Nat Neurosci 13:610-614. CrossRef Medline

Reddy KC, Andersen EC, Kruglyak L, Kim DH (2009) A polymorphism in npr-1 is a behavioral determinant of pathogen susceptibility in C. elegans. Science 323:382-384. CrossRef Medline

Rex E, Molitor SC, Hapiak V, Xiao H, Henderson M, Komuniecki R (2004) Tyramine receptor (SER-2) isoforms are involved in the regulation of pharyngeal pumping and foraging behavior in Caenorhabditis elegans. J Neurochem 91:1104-1115. CrossRef Medline

Rex E, Hapiak V, Hobson R, Smith K, Xiao H, Komuniecki R (2005) TYRA-2 (F01E11.5): a Caenorhabditis elegans tyramine receptor expressed in the MC and NSM pharyngeal neurons. J Neurochem 94: 181-191. CrossRef Medline

Rogers C, Reale V, Kim K, Chatwin H, Li C, Evans P, de Bono M (2003) Inhibition of Caenorhabditis elegans social feeding by FMRFamiderelated peptide activation of NPR-1. Nat Neurosci 6:1178-1185. CrossRef Medline

Rogers C, Persson A, Cheung B, de Bono M (2006) Behavioral motifs and neural pathways coordinating $\mathrm{O} 2$ responses and aggregation in C. elegans. Curr Biol 16:649-659. CrossRef Medline

Sanyal S, Wintle RF, Kindt KS, Nuttley WM, Arvan R, Fitzmaurice P, Bigras E, Merz DC, Hébert TE, van der Kooy D, Schafer WR, Culotti JG, Van Tol HH (2004) Dopamine modulates the plasticity of mechanosensory responses in Caenorhabditis elegans. EMBO J 23:473-482. CrossRef Medline

Sawin ER, Ranganathan R, Horvitz HR (2000) C. elegans locomotory rate is modulated by the environment through a dopaminergic pathway and by experience through a serotonergic pathway. Neuron 26:619-631. CrossRef Medline

Speese S, Petrie M, Schuske K, Ailion M, Ann K, Iwasaki K, Jorgensen EM, Martin TF (2007) UNC-31 (CAPS) is required for dense-core vesicle but not synaptic vesicle exocytosis in Caenorhabditis elegans. J Neurosci 27: 6150-6162. CrossRef Medline
Styer KL, Singh V, Macosko E, Steele SE, Bargmann CI, Aballay A (2008) Innate immunity in Caenorhabditis elegans is regulated by neurons expressing NPR-1/GPCR. Science 322:460-464. CrossRef Medline

Suo S, Kimura Y, Van Tol HH (2006) Starvation induces cAMP response element-binding protein-dependent gene expression through octopamine-Gq signaling in Caenorhabditis elegans. J Neurosci 26:1008210090. CrossRef Medline

Tomioka M, Adachi T, Suzuki H, Kunitomo H, Schafer WR, Iino Y (2006) The insulin/PI 3-kinase pathway regulates salt chemotaxis learning in Caenorhabditis elegans. Neuron 51:613-625. CrossRef Medline

Trent C, Tsuing N, Horvitz HR (1983) Egg-laying defective mutants of the nematode Caenorhabditis elegans. Genetics 104:619-647. Medline

Tsalik EL, Niacaris T, Wenick AS, Pau K, Avery L, Hobert O (2003) LIM homeobox gene-dependent expression of biogenic amine receptors in restricted regions of the C. elegans nervous system. Dev Biol 263:81-102. CrossRef Medline

Waggoner LE, Hardaker LA, Golik S, Schafer WR (2000) Effect of a neuropeptide gene on behavioral states in Caenorhabditis elegans egg-laying. Genetics 154:1181-1192. Medline

Wragg RT, Hapiak V, Miller SB, Harris GP, Gray J, Komuniecki PR, Komuniecki RW (2007) Tyramine and octopamine independently inhibit serotonin-stimulated aversive behaviors in Caenorhabditis elegans through two novel amine receptors. J Neurosci 27:13402-13412. CrossRef Medline

Zhang Y, Lu H, Bargmann CI (2005) Pathogenic bacteria induce aversive olfactory learning in Caenorhabditis elegans. Nature 438:179-184. CrossRef Medline

Zimmer M, Gray JM, Pokala N, Chang AJ, Karow DS, Marletta MA, Hudson ML, Morton DB, Chronis N, Bargmann CI (2009) Neurons detect increases and decreases in oxygen levels using distinct guanylate cyclases. Neuron 61:865-879. CrossRef Medline 